\title{
Phenological versus meteorological controls on land-atmosphere water and carbon fluxes
}

\author{
Michael J. Puma, ${ }^{1,2}$ Randal D. Koster, ${ }^{3}$ and Benjamin I. Cook $^{2}$ \\ Received 30 May 2012; revised 16 November 2012; accepted 21 November 2012; published 25 January 2013.
}

[1] Phenological dynamics and their related processes strongly constrain land-atmosphere interactions, but their relative importance vis-à-vis meteorological forcing within general circulation models (GCMs) is still uncertain. Using an off-line land surface model, we evaluate leaf area and meteorological controls on gross primary productivity, evapotranspiration, transpiration, and runoff at four North American sites, representing different vegetation types and background climates. Our results demonstrate that compared to meteorological controls, variation in leaf area has a dominant control on gross primary productivity, a comparable but smaller influence on transpiration, a weak influence on total evapotranspiration, and a negligible impact on runoff. Climate regime and characteristic variations in leaf area have important modulating effects on these relative controls, which vary depending on the fluxes and timescales of interest. We find that leaf area in energylimited evaporative regimes tends to exhibit greater control on annual gross primary productivity than in moisture-limited regimes, except when vegetation exhibits little interannual variation in leaf area. For transpiration, leaf area control is somewhat less in energylimited regimes and greater in moisture-limited regimes for maximum pentad and annual fluxes. These modulating effects of climate and leaf area were less clear for other fluxes and at other timescales. Our findings are relevant to land-atmosphere coupling in GCMs, especially considering that leaf area variations are a fundamental element of land use and land cover change simulations.

Citation: Puma, M. J., R. D. Koster, and B. I. Cook (2013), Phenological versus meteorological controls on landatmosphere water and carbon fluxes, J. Geophys. Res. Biogeosci., 118, 14-29, doi:10.1029/2012JG002088.

\section{Introduction}

[2] Numerous climate modeling efforts are focused on improving our understanding of the complex interactions between the land surface and atmosphere, motivated by diverse needs ranging from precipitation generation [Guo et al., 2006] to improving our understanding of land use-land cover change (LULCC) impacts on biogeochemical cycling and climate [e.g., Friedlingstein et al., 2006; Shevliakova et al., 2009; Pitman et al., 2011]. To meet these needs, dynamic global vegetation models (DGVMs) are increasingly being integrated into general circulation models (GCMs) [e.g., Foley et al., 1996; Bonan et al., 2003; Zeng et al., 2002; Sitch et al., 2003; Krinner et al., 2005; Bonan and Levis, 2006;

\footnotetext{
${ }^{1}$ Center for Climate Systems Research, Columbia University, New York, New York, USA. USA.

${ }^{2}$ NASA Goddard Institute for Space Studies, New York, New York,

${ }^{3}$ Global Modeling and Assimilation Office, NASA Goddard Space Flight Center, Greenbelt, Maryland, USA.

Corresponding author: M. J. Puma, Center for Climate Systems Research, Columbia University, 2880 Broadway, New York, NY 10025, USA. (mjp38@columbia.edu)

(C)2012. American Geophysical Union. All Rights Reserved. 2169-8953/13/2012JG002088
}

Shevliakova et al., 2009] with the goal of improving the representation of vegetation controls on photosynthesis, respiration, transpiration, surface energy fluxes, and carbon and nutrient allocation [e.g., Quillet et al., 2010]. Yet, a recent inter-comparison study on LULCC found significant variability in model responses to LULCC, including a lack of consistency in how LULCC affects available energy partitioning between latent and sensible heat [Noblet-Ducoudré et al., 2012]. These diverse model responses, a partial consequence of increasing land model complexity, highlight the need to better understand the impacts of additional vegetation dynamics as they are added to climate models.

[3] One of the primary vegetation dynamics categories that are poorly understood in a GCM context is vegetation phenology. Phenological controls on land-atmosphere interactions in GCMs have been studied to clarify the characteristics of the connections between phenology and global temperature, precipitation, and other climate variables [e.g., $\mathrm{Lu}$ and Shuttleworth, 2002; Kim and Wang, 2005; Stöckli et al., 2008a]. In particular, phenology plays an important role in these physical feedback processes through changes in leaf area index (LAI) [e.g., Liu et al., 2008; Morisette et al., 2008]. The potential influence of phenology on land-atmosphere interactions is still, however, not well understood, despite the fact that the causal link between climate and phenology is conceptually straightforward [Alessandri et al., 2007; Morisette et al., 2008]. Phenological change, for example, can lead to shifts 
in the surface energy balance and partitioning, which can then modify surface temperatures, humidity, and circulation.

[4] Presently, GCMs either prescribe phenology (primarily through specification of leaf area index) [e.g., Friend and Kiang, 2005; Lawrence and Chase, 2007] or compute phenological variables prognostically [e.g., Sitch et al., 2003; Krinner et al., 2005; Shevliakova et al., 2009]. In the former case, phenology is not responsive to the model's surface climatic states (e.g., soil moisture, temperature, and solar radiation). In the latter case, phenology does respond to climate variations, but the effect of climate biases on phenology is then an issue [Kucharik et al., 2006; Morisette et al., 2008; Stöckli et al., 2008a] making it difficult to predict LAI accurately within land models [Liu et al., 2008].

[5] Many modeling studies have looked at the influence of phenology on land-atmosphere fluxes [e.g., Buermann et al., 2001; Bonan et al., 2002; Lu and Shuttleworth, 2002; Kang et al., 2007; Kim and Wang, 2007], on growing season length and carbon fluxes [e.g., White and Nemani, 2003; Piao et al., 2007; Richardson et al., 2010; Muraoka et al., 2010], and on longer-term dynamics like tree competition [e.g., Kramer et al., 2000]. In fact, many authors have made substantial progress in advancing our understanding of the relative control of different variables that are important for prognostic phenology models. For example, Richardson et al. [2007] investigated the relative control of meteorological forcings compared to the biotic response to meteorological variables for a spruce-dominated forest. Alton et al. [2007] explored the relative control of biophysical parameters and model processes that govern light propagation and canopy photosynthesis for three forest biomes.

[6] Our interest, however, is on the relative importance of phenological and meteorological variables on terrestrial carbon and water fluxes in the GCM context. This is important, because many GCMs today still prescribe climatological seasonal cycles of vegetation phenology. Given that an obvious and imminent development step for these GCMs is the inclusion of variable phenology, the impact of such variations on the simulation of the surface fluxes that affect simulated climate must be addressed through careful analysis. Our study is a contribution to that analysis. Note that because poor simulation of meteorological variables is common in GCMs, a determination that meteorological variability is more important than phenological variability for fluxes of interest may point to meteorological bias correction as a more fruitful development path for certain model applications than the development of a prognostic phenology routine.

[7] One key study by Guillevic et al. [2002] made progress on this question by exploring the relative controls of inter-annual LAI and atmospheric variability on evapotranspiration using the Mosaic land surface model [Koster and Suarez, 1992] in both off-line mode and coupled to a GCM. The authors found a regional dependence of phenological influence on evapotranspiration, where the impacts of LAI variability were less both for dense vegetation cover (due to a saturation effect) and for regions where vegetation experience substantial water stress. They also point out that precipitation variability tends to have a stronger impact on surface fluxes than LAI and that atmospheric variability is the dominate influence in their coupled experiments.

[8] Here we investigate the relative control of LAI and atmospheric variables on terrestrial fluxes of carbon and water, building on the work of Guillevic et al. [2002]. Our objective is to quantify and compare the strength of LAI and meteorological controls on gross primary production, evapotranspiration, transpiration, and runoff - all key land surface fluxes in GCMs - for a range of climate regimes and vegetation. Experiments are designed specifically to assess the effects of inter-annual variability in these forcings on annual fluxes as well as on maximum values and their timing at the sub-annual timescale. We also explore whether the contemporaneous nature of LAI and meteorology act together to have an impact on carbon and water fluxes.

[9] We note that the experiments are conducted with a specific land surface model; numerous studies have demonstrated substantial variation among the output of land surface models due to differences in model parameterizations and forcings [e.g., Henderson-Sellers et al., 1995; Dirmeyer et al., 2006; Jiménez et al., 2011]. To address this issue, we evaluate model performance relative to observations from AmeriFlux sites and also highlight important limitations associated with this evaluation.

\section{Methods and Model}

[10] We select four sites in the United States (Figure 1), spanning a range of climate regimes and vegetation, to explore the relative controls of phenology (through leaf area) and atmospheric variables on terrestrial fluxes at spatial scales typically associated with global land and climate models. The northeast United States (NE) site, located in New York state, is covered mainly by deciduous and evergreen forest. The southern United States (S) site is mainly an agricultural site (primarily including soybean, maize, and cotton crops) in Tennessee, while the western United States (W) site in western Colorado is a mixture of mainly shrubs, woodland, grassland, and evergreen forest. The driest location, the far west United States (FW) site in Arizona near the southern border with California, is mainly shrubs and bare soil.

[11] Figure 1 also identifies the locations of three AmeriFlux sites (Harvard Forest, HF; Bondville, B; and Niwot Ridge, NR). We select these AmeriFlux sites to validate model performance in water and carbon flux simulation, as they have observations of latent heat, sensible heat, and gross primary productivity fluxes. These AmeriFlux sites are used for validation only, because gap-filled meteorological and LAI data are not generally available for as long a period (i.e., 17 years) as at our four experimental sites.

[12] Figure 2a shows the relationship between annual precipitation and temperature, while Figure $2 \mathrm{~b}$ presents the coefficient of variation $(\mathrm{CV})$ of annual precipitation versus the standard deviation of annual temperature at our four sites. The marker color indicates each site's evaporative fraction (EF), which is the ratio of the site's annual latent heat flux to the sum of its annual latent and sensible heat fluxes (computed using the GISS land surface model, as described below). EF is a measure of whether evapotranspiration is soil moisture or energy limited. Low EF values (near zero) are indicative of arid and semiarid regions, with high-energy inputs and low available soil moisture. High EF values (near unity) are typical in humid regions with high soil moisture availability, which is generally sufficient to satisfy (atmospheric) evaporative demand. 


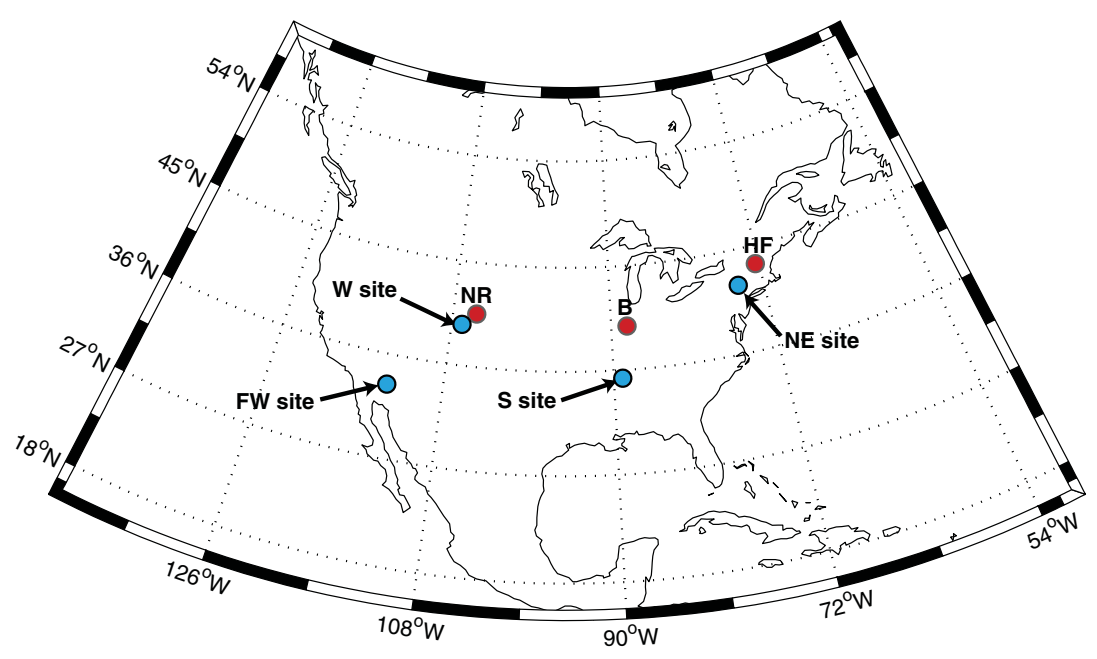

Figure 1. Site locations for our experimental analyses plus the three AmeriFlux sites for model validation. The experimental sites are $1^{\circ}$ by $1^{\circ}$ grid cells located in the northeast United States $\left(41.5^{\circ} \mathrm{N}\right.$, $\left.74.5^{\circ} \mathrm{W}\right)$, southern United States $\left(35.5^{\circ} \mathrm{N}, 89.5^{\circ} \mathrm{W}\right)$, western United States $\left(39.5^{\circ} \mathrm{N}, 106.5^{\circ} \mathrm{W}\right)$, and far west United States $\left(33.5^{\circ} \mathrm{N}, 114.5^{\circ} \mathrm{W}\right)$. The AmeriFlux sites include Harvard Forest $\left(\mathrm{HF} ; 42.54^{\circ} \mathrm{N}\right.$, $\left.72.17^{\circ} \mathrm{W}\right)$, Bondville $\left(\mathrm{B} ; 40.01^{\circ} \mathrm{N}, 88.29^{\circ} \mathrm{W}\right)$, and Niwot Ridge (NR; 40.03 $\left.\mathrm{N}, 105.55^{\circ} \mathrm{W}\right)$.

[13] Evapotranspiration is typically energy limited for the $\mathrm{NE}$ and $\mathrm{S}$ sites $(\mathrm{EF} \approx 0.6$ for both), meaning that on average the soil moisture is high enough to satisfy atmospheric demand. Conversely, soil moisture generally controls evapotranspiration at the $\mathrm{W}$ site $(\mathrm{EF} \approx 0.4)$, and it is even more limiting at the $\mathrm{FW}$ site $(\mathrm{EF} \approx 0.1)$. With regard to annual temperature, the $\mathrm{W}$ site is the coolest, while the FW site is the warmest. Besides mean annual climate, we also look at the inter-annual variability of temperature and precipitation. The standard deviation of annual temperature is similar for the four sites $(\approx 0.6 \mathrm{~K})$, but precipitation inter-annual variability is somewhat different (Figure 2). The NE and $\mathrm{S}$ sites have low CV values, while the drier (W and FW) sites have larger $\mathrm{CV}$ values ( $\approx 0.2$ and 0.4 , respectively).

\subsection{GISS LSM}

[14] All model experiments were conducted with the land surface model (LSM) of the NASA Goddard Institute for Space Studies (GISS) ModelE, a state-of-the-art atmosphere global climate model [Schmidt et al., 2006; Hansen et al., 2007]. Previous versions of the ModelE have been used to investigate soil moisture dynamics [Krakauer et al., 2010], the interactions between vegetation and climate [Hasler et al., 2009], and the connections between irrigation and climate [Puma and Cook, 2010; Cook et al., 2011]. Here we model a $1^{\circ}$ by $1^{\circ}$ grid cell (a resolution that approximately corresponds to the new standard resolution of ModelE) at each of the four U.S. sites. We use the GISS LSM in "off-line mode," meaning that a data set of meteorological forcings (described below) is used to drive the model. One advantage to our off-line approach is that we avoid the large climate biases typically associated with GCM simulations; another is that we do not have to deal with uncertainties in land-atmosphere feedbacks.

[15] The GISS LSM includes both soil and vegetation modules that compute water, carbon, and energy dynamics of the land surface. The soil module represents the land as a $3.5 \mathrm{~m}$ soil column, which is discretized into six layers.
The details of the model's soil moisture, soil heat, and evapotranspiration dynamics are described in Abramopoulos et al. [1988], Rosenzweig and Abramopoulos [1997], and Aleinov and Schmidt [2006]. The vegetation module of the GISS LSM computes photosynthesis using the Farquhar photosynthesis model [Farquhar et al., 1980, 1982]. Stomatal conductance is based on the widely used canopy conductance model of Ball et al. [1987]. The approach for representing the vertical distribution of canopy radiation is as described in Friend and Kiang [2005], which was based on Spitters [1986].

\subsection{AmeriFlux Data}

[16] The AmeriFlux network, which is part of the global FLUXNET network, is a collection of sites with micrometeorological towers, which use the eddy covariance technique to measure $\mathrm{CO}_{2}$, latent heat, and sensible heat fluxes [Baldocchi et al., 2001]. FLUXNET sites have been used extensively for evaluation, calibration, and parameterization of ecosystem and land surface models [e.g., Friend et al., 2007; Wang et al., 2007; Stöckli et al., 2008b; Williams et al., 2009]. Here we follow the approach of Stöckli et al. [2008b] to evaluate the performance of the GISS LSM in terms of its predictions of carbon, water, and energy fluxes using AmeriFlux observations.

[17] We select three AmeriFlux sites (Figure 1) based on data availability that approximately cover the range of vegetation and climate zone in our experiment (with the exception of the arid FW site). The Harvard Forest site is characterized as deciduous forest (using the Matthews [1984] types) with a sandy loam soil [Urbanski et al., 2007]. Bondville is cropland, rotated on an annual basis between corn and soybean, on silt loam soil [Meyers and Hollinger, 2004]. Niwot Ridge, the western AmeriFlux site, is an evergreen forest on a clay soil [Monson et al., 2002].

[18] The atmospheric forcings for these three sites are taken from a consistently gap-filled meteorological forcing data set developed and generously shared by Stöckli et al. [2008b], which was based on the original level 2 AmeriFlux 


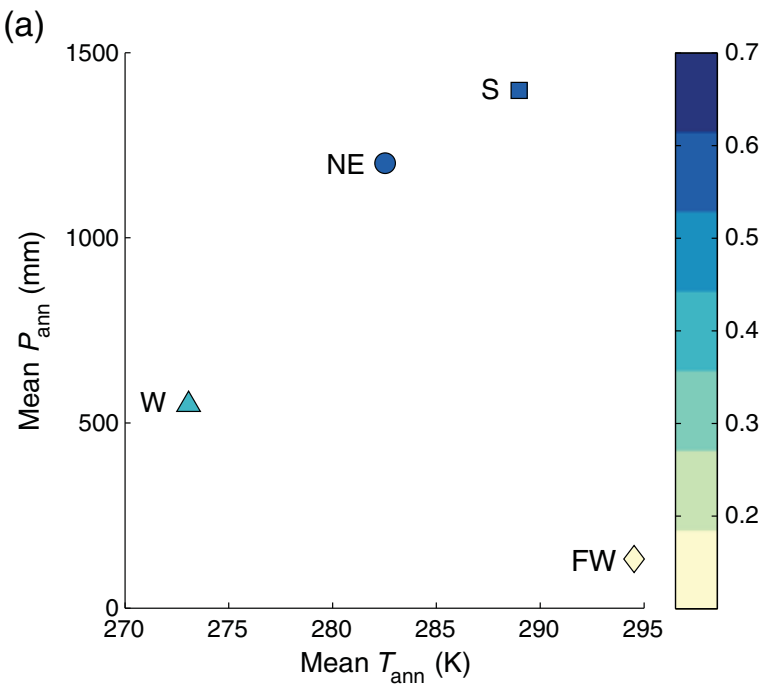

(b)

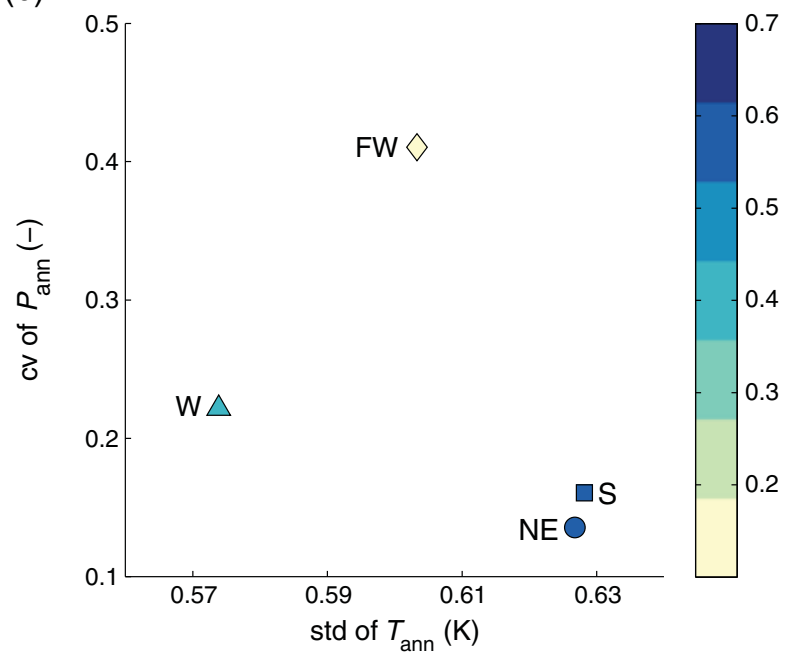

Figure 2. Climate characteristics of the four sites based on 1982-1998 meteorological data from Sheffield et al. [2006]. (a) Relationship between annual mean temperature, precipitation, and evaporative fraction (EF). (b) Relationship between coefficient of variation (CV) for annual temperature, $\mathrm{CV}$ for annual precipitation, and $\mathrm{EF}$.

data. (For details on the gap-filling methodology, readers are referred to Stöckli et al. [2008b].) These data are at a temporal resolution of $30 \mathrm{~min}$ (Bondville, Niwot Ridge) or $60 \mathrm{~min}$ (Harvard Forest). Beside this meteorological data set, we also specify the leaf area index (LAI), because the model's phenological dynamics are prescribed (rather than prognostically computed). We use LAI data from the Collection 4 MODIS LAI (MOD15A2) product, which is available starting from February 2000 [Oak Ridge National Laboratory Distributed Active Archive Center, 2011]. These 8 day LAI data are smoothed using a 5 day moving average and are interpolated to match the time step of the atmospheric forcing data. The meteorological and LAI data sets allow us to simulate fluxes for the years 2001 to 2002 at the Harvard Forest site and the years 2002 to 2005 at both Bondville and Niwot Ridge.

[19] Our model-simulated fluxes are compared against Ameriflux data for latent heat (LE) flux, sensible heat $(\mathrm{H})$ flux, and gross primary productivity (GPP) to assess model realism in terms of magnitude, timing, and phase of these fluxes. Simulated LE and H fluxes are compared against level 2 data when the friction velocity $\left(u^{*}\right)$ is above $0.2 \mathrm{~m}$, which allows us to account for biases in eddy covariance measurements during low-turbulence periods [Schmid et al., 2003; Stöckli et al., 2008b]. The level 2 data set is not gap filled, which avoids the imposition of a priori relationships on the observations. In the case of GPP, only net ecosystem exchange (NEE, which is the difference between GPP and ecosystem respiration) data are available in the level 2 data set. We therefore use the level 4 data set because it includes estimates of GPP. The estimates are obtained by applying a "flux-partitioning algorithm" to separate NEE into GPP and ecosystem respiration through the use of gap-filled NEE (filled by the marginal distribution sampling method) and ecosystem respiration (computed using an algorithm that defines a short-term temperature response of the respiration based on NEE) [Reichstein et al., 2005].

[20] We account for both random and systematic errors in the LE and H observations as done by Stöckli et al. [2008b]. In particular, we use the empirical work of Richardson et al. [2006] to estimate the random uncertainties based on season, flux type, and vegetation type. For systematic errors, we focus on those associated with the failure in energy balance closure. This is done by computing the residual in energy balance closure at each site through a regression of observed net radiation versus the sum of LE and $\mathrm{H}$ fluxes [Wilson et al., 2002; Grünwald and Bernhofer, 2007]. We then compute and plot the total (random and systematic) errors for each analysis time step (i.e., 10 days) by summing the squares of the random and systematic errors and then taking the square root of this sum [Stöckli et al., 2008b).

\subsection{Experimental Data}

[21] The atmospheric forcings are from a near-surface meteorological data set by Sheffield et al. [2006], which were specifically developed for driving land surface models. This data set was created by blending reanalysis data with observations for the years 1948 to 2008 and is available at a 3-hourly, $1^{\circ}$ by $1^{\circ}$ resolution globally. We select a subset of this meteorological data (1982-1998) based on the years of LAI data availability. These data are presented in Figure 3, where individual years of data are shown by the gray lines and the mean monthly values are shown by the blue line.

[22] A leaf area index data set is needed for GISS LSM simulations, because the model's phenological dynamics are prescribed (rather than prognostically computed). The advanced very high resolution radiometers (AVHRR) provides the longest continuous global time series of LAI data (starting in July 1981) suitable for vegetation studies [Tucker et al., 2005; Ganguly et al., 2008]. Although the NASA Moderate Resolution Imaging Spectroradiometer (MODIS) makes higher quality spectral and angular measurements starting from February 2000, it is not available for as many years as the AVHRR data. We therefore use the 17 year AVHRR total LAI data set (1982 to 1998, excluding 1981 data) from the International Satellite Land Surface Climatology Project (ISLSCP) Initiative II Data Collection [Sietse, 2010] to take advantage of its longer record.

[23] The AVHRR LAI data are biased high when compared to MODIS LAI data; consequently, we adjust the AVHRR 

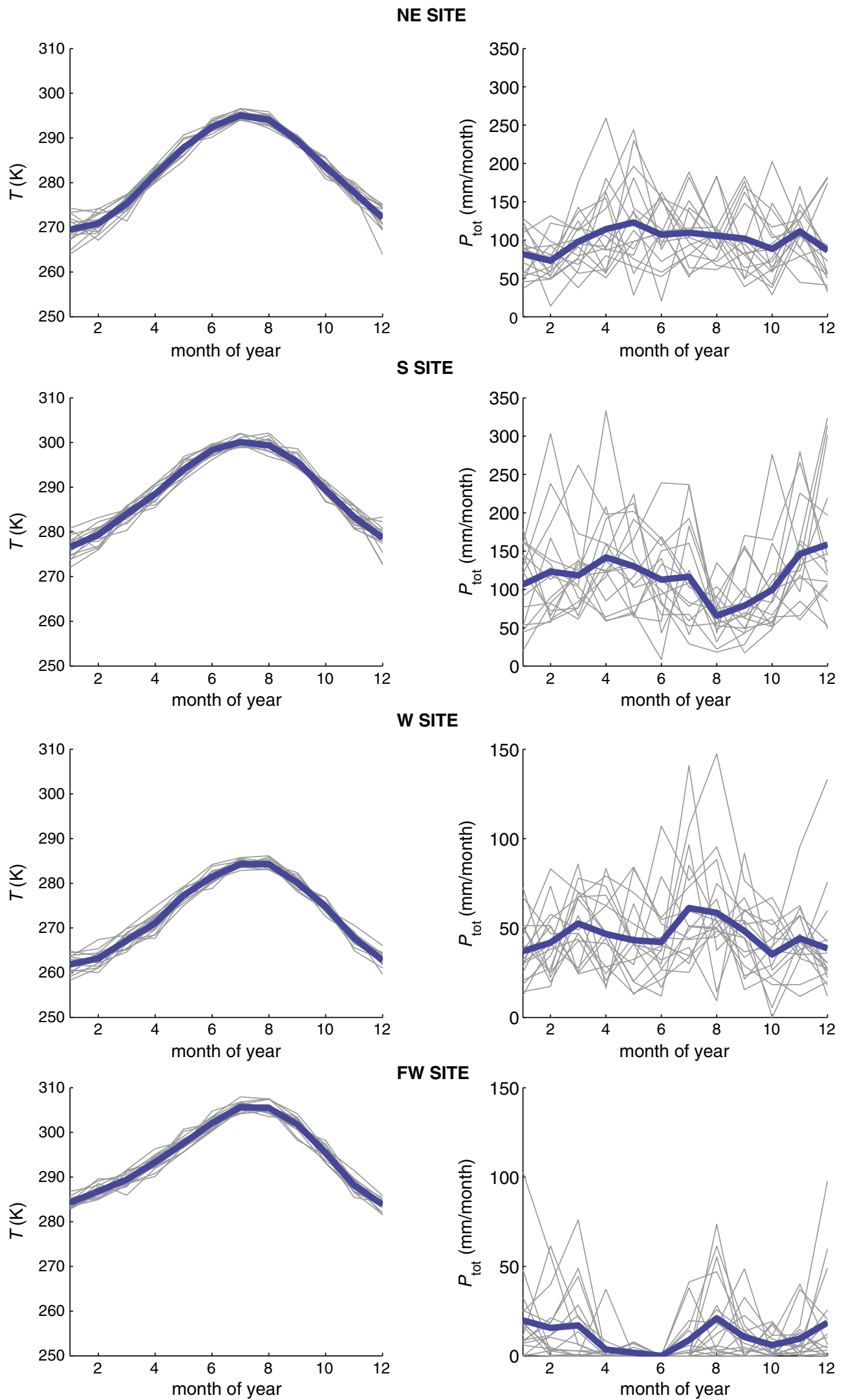

FW SITE

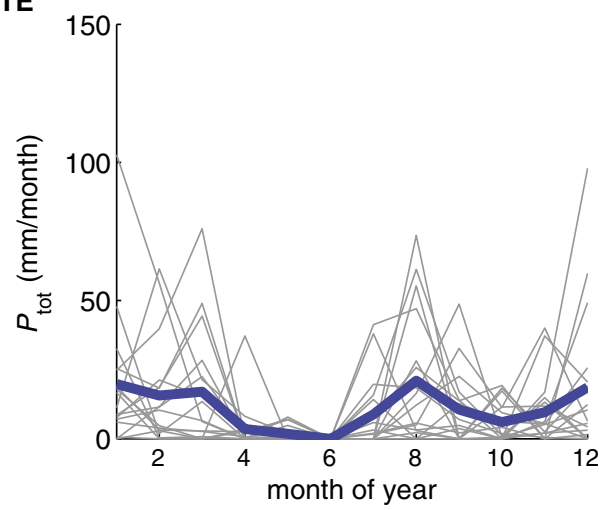

Figure 3. Monthly (left) temperature and (right) precipitation based on 1982-1998 data for the four sites. Mean monthly values are shown by the blue line, while individual year monthly values are shown with the gray lines. 
LAI to remove the high bias, in part because the vegetation parameters of the GISS LSM were selected to match observed carbon fluxes when using prescribed MODIS LAI data. The LAI adjustment is made using a quantile-based mapping technique, a method used for many hydrologic and other studies [Li et al., 2010]. Specifically, the cumulative density function (CDF) of the AVHRR data was adjusted to match the CDF from the Collection 4 MODIS LAI (MOD15A2) product for the years 2001 to 2010 . Smooth nonparametric estimates of these CDFs were computed using kernal estimation available in the MATLAB Statistics Toolbox [Bowman and Azzalini, 1997]. The nonparametric inverse CDF of the MODIS data was then used to generate the adjusted AVHRR LAI data. The adjusted AVHRR data are presented in Figure 4 for each site; gray lines correspond to individual years of LAI data and the blue line corresponds to the mean monthly values. We note for the NE site that although LAI during the peak of the growing season is not likely to vary dramatically from year to year given the characteristics of the forest cover in the region, the constant peak LAI is a partial consequence of limitations associated with AVHRR measurements.

[24] The land cover for each of the four sites is based on the $1^{\circ}$ by $1^{\circ}$ land cover map from the ISLSCP II data set [DeFries and Hansen, 2010], where land cover is categorized into the 13 modified International Geosphere Biosphere Program classes. This land cover information is then converted to the corresponding bare soil and vegetation categories (eight vegetation types described by Matthews [1984]) that are used by the GISS LSM (Table 1). We note that although the FW site is designated to be $19 \%$ bare soil, the total bare soil fraction is higher, as the shrub category includes interspersed bare soil. The shrub and interspersed bare soil are represented as a single "tile," which is the standard approach for the GISSLSM and many other global-scale models.

[25] As with the vegetation cover and LAI data, soil textures (sand, silt, and clay fractions) are also from ISLSCP II [Scholes and Brown de Colstoun, 2011], which contains soil parameters on a $1^{\circ}$ by $1^{\circ}$ grid for two soil depths (0-30 and

Table 1. Matthews [1984] Land Cover in Each $1^{\circ}$ by $1^{\circ}$ Grid Cell Based on ISLSCP II Land Cover Data ${ }^{a}$

\begin{tabular}{lcccc}
\hline Land Cover & NE Site & S Site & W Site & FW Site \\
\hline Grassland & 0 & 0.02 & 0.18 & 0.01 \\
Shrub & 0.04 & 0.18 & 0.18 & 0.74 \\
Woodland & 0.02 & 0.10 & 0.33 & 0 \\
Deciduous forest & 0.57 & 0.06 & 0.01 & 0 \\
Evergreen forest & 0.34 & 0.07 & 0.23 & 0 \\
Crops & 0 & 0.56 & 0.08 & 0.06 \\
Bare Soil & 0.03 & 0.02 & 0 & 0.19 \\
\hline
\end{tabular}

${ }^{\mathrm{a}}$ See DeFries and Hansen [2010].
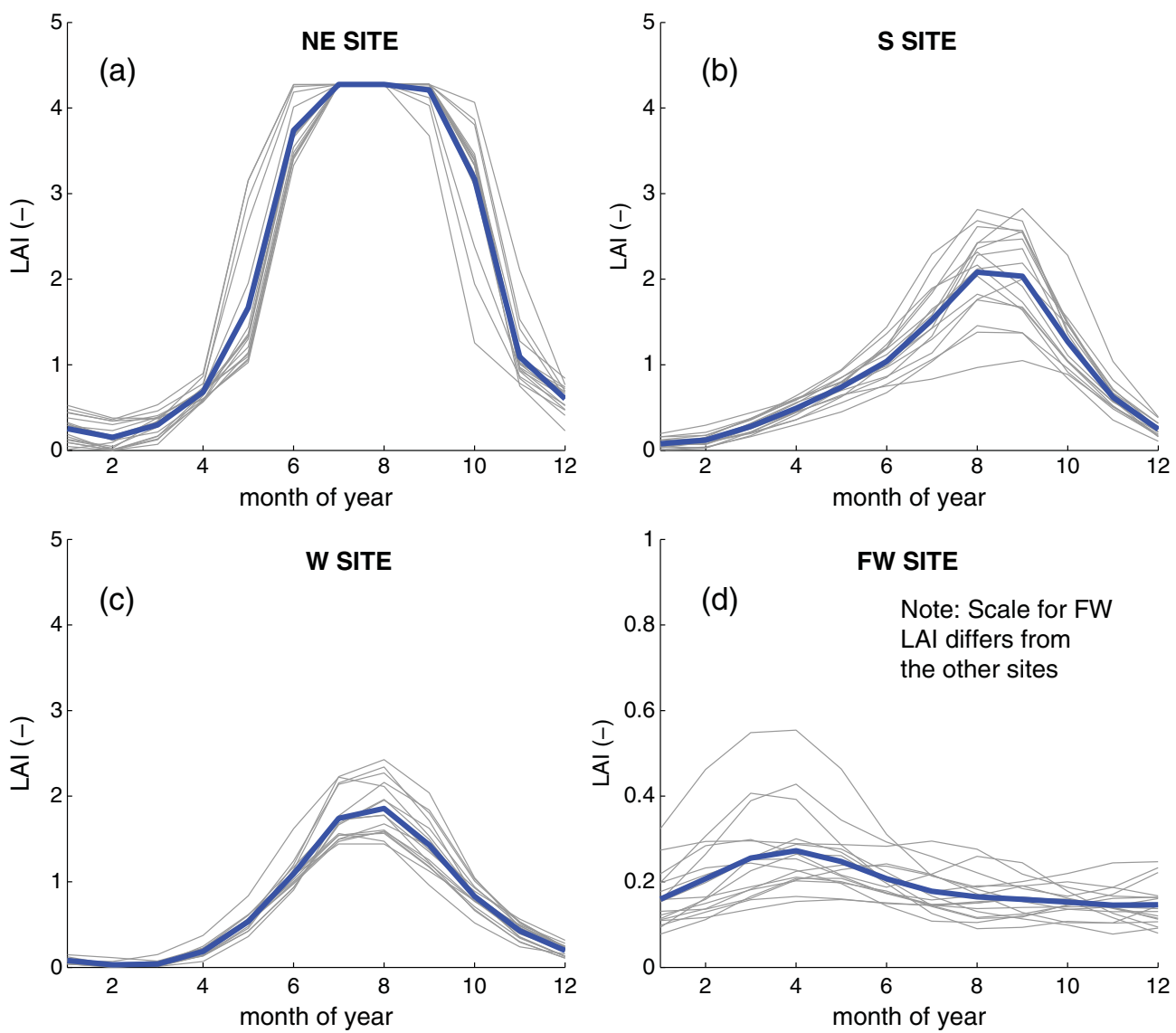

Figure 4. Monthly LAI from the AVHRR global data set (adjusted using MODIS data) for 1982-1998 data at the four sites: (a) northeast U.S. site, (b) southern U.S. site, (c) western U.S. site, and (d) far west U. $\mathrm{S}$. site. Mean monthly values are shown by the blue line, while individual year monthly values are shown with the gray lines. 
$0-150 \mathrm{~cm})$. The soil textures for the four sites are shown in Table 2. Other land-related parameters are as described in Abramopoulos et al. [1988] and Rosenzweig and Abramopoulos [1997].

\section{Experimental Design}

[26] The experimental setup, presented schematically in Figure 5, is designed to assess the relative control of both leaf area variations and meteorological variations on variations in terrestrial carbon and water fluxes. For each site, we run individual yearlong simulations for every combination of the yearly LAI and atmospheric data, which results in 289 realizations (i.e., 17 LAI years $\times 17$ meteorological years). All experiments are initialized using the climatological

Table 2. Soil Textures Fractions for Two Soil Depths (0-30 and $0-150 \mathrm{~cm})$ at the Four Sites Based on ISLSCP II Soil Data ${ }^{\mathrm{a}}$

\begin{tabular}{lcccc}
\hline Soil Texture & NE Site & S Site & W Site & FW Site \\
\hline Sand fraction $(0-30 \mathrm{~cm})$ & 0.36 & 0.40 & 0.42 & 0.57 \\
Silt fraction $(0-30 \mathrm{~cm})$ & 0.33 & 0.36 & 0.36 & 0.26 \\
Clay fraction $(0-30 \mathrm{~cm})$ & 0.31 & 0.24 & 0.22 & 0.17 \\
Sand fraction $(0-150 \mathrm{~cm})$ & 0.42 & 0.40 & 0.40 & 0.51 \\
Silt fraction $(0-150 \mathrm{~cm})$ & 0.30 & 0.33 & 0.31 & 0.28 \\
Clay fraction $(0-150 \mathrm{~cm})$ & 0.28 & 0.27 & 0.29 & 0.21 \\
\hline
\end{tabular}

\footnotetext{
${ }^{\mathrm{a}}$ See Scholes and Brown de Colstoun [2011]. The 0-30 cm soil textures are assigned to the top two GISS LSM soil layers (thicknesses of 0.1 and $0.17 \mathrm{~m}$, respectively), and the $0-150 \mathrm{~cm}$ data are assigned to the bottom four layers (thicknesses of $0.30,0.51,0.89$, and 1.53 , respectively.)
}

soil moisture and soil heat values for January based on a 17 year model run with each site's actual LAI and meteorological data from 1982 to 1998 . From these simulations, we compute two sets of average values to explore the control of LAI variability (LAI_v) and meteorological variability (MET_v) on carbon and water fluxes. Each member of the first set of average values is the average across simulations run with a single LAI year but different meteorological years, so that the effect of the meteorological variability is averaged out. The distribution of these average values $\left(\bar{X}_{\text {lai1 }} \ldots \bar{X}_{\text {lai17 }}\right.$ shown in the blue boxes of Figure 5) reflects the impact of varying LAI on carbon and water fluxes. For a given member of the second set, the average flux values are computed across simulations that use the same meteorological year but different LAI years, so that the effect of LAI variability is averaged out. The distribution of this second set of average values $\left(\bar{X}_{\text {met1 }} \ldots \bar{X}_{\text {met17 }}\right.$ presented in the red boxes of Figure 5) reflects the impact of varying meteorological forcings on terrestrial fluxes.

[27] In addition to these two sets of average values, the shaded boxes along the diagonal have a special significance, because the LAI and meteorological data set are from the same year. Therefore, the terrestrial fluxes corresponding to these shaded boxes represent the fluxes due to the actual historical LAI and meteorological forcings at each site. We analyze the distribution of these "actual" fluxes (relative to the fluxes from all of the realizations) to investigate whether the contemporaneous nature of extreme LAI values and meteorological conditions can exacerbate the extremes of carbon and water fluxes.

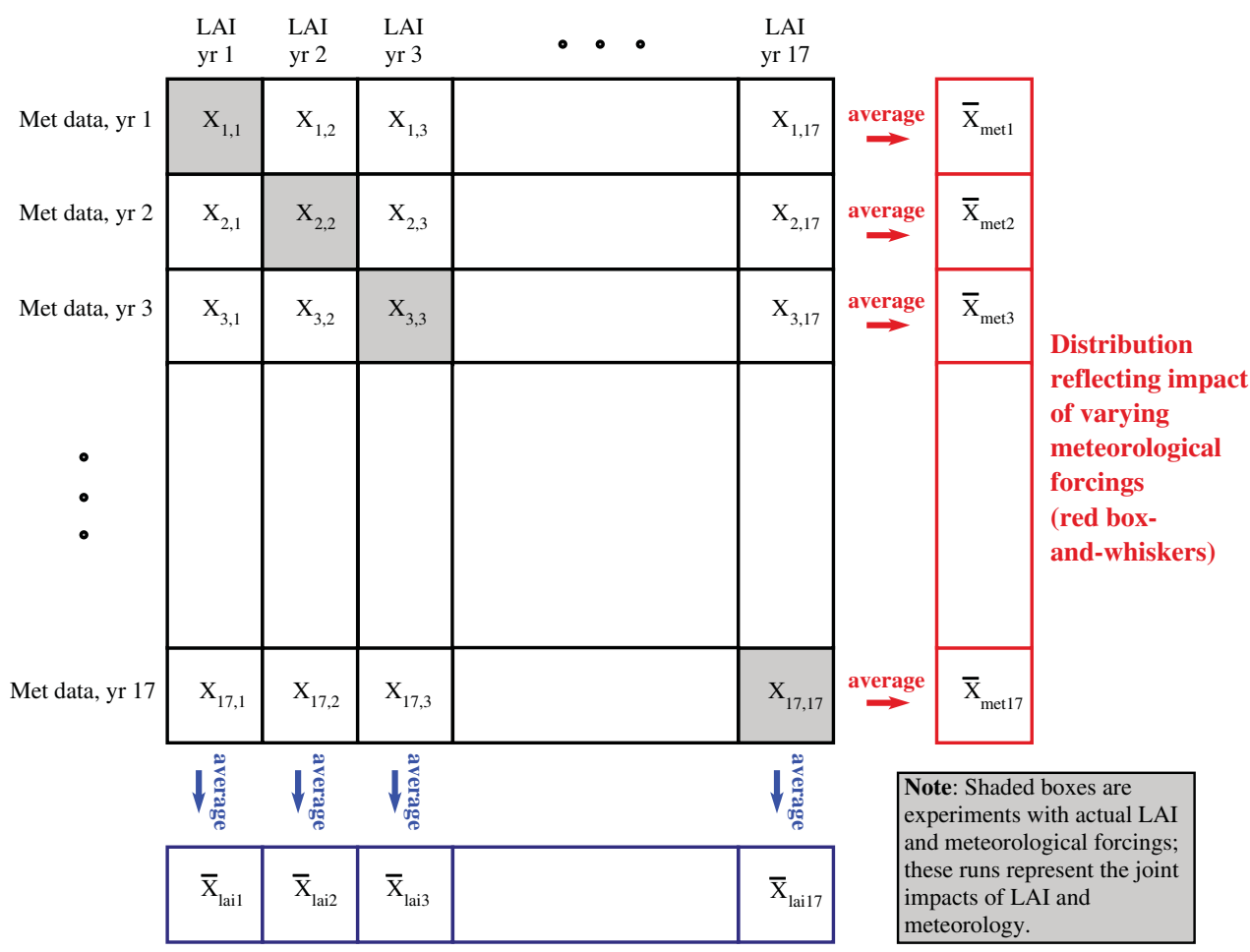

Distribution reflecting impact of varying LAI (blue box-and-whiskers)

Figure 5. Schematic diagram of the experimental setup to assess the relative control of leaf area index and meteorological variables on terrestrial carbon and water fluxes for the four experimental sites. 


\section{Results}

\subsection{Model Validation}

[28] The model simulates GPP fluxes well in terms of timing; this is especially true at Harvard Forest (Figure 6). The additional model skill in terms of GPP fluxes at Harvard Forest is partially related to the original vegetation model development, which involved selection of biophysical parameters that are both consistent with the site's vegetation and allow accurate simulation of GPP fluxes. At Bondville, the small springtime increases in GPP missed by the model are not reflected by corresponding increases in MODIS LAI data (not shown). Similarly, the delayed springtime greenup and early senescence at Niwot Ridge is consistent with the MODIS LAI timing. In terms of magnitude, the GISS LSM matches the Harvard Forest fluxes very well but underestimates the peak growing season LAI at the other two sites. However, full evaluation and attribution of this underestimation is outside the scope of this paper, as it requires detailed knowledge of the uncertainties associated with GPP estimates. These uncertainties can be substantial due to both gap-filling issues and the assumptions associated with ecosystem respiration modeling [Falge et al., 2002; Hagen et al., 2006].

[29] Overall, the LE and H fluxes simulated by the GISS LSM are in close agreement with observations, as shown in Figures 7 and 8. At Harvard Forest, simulated LE fluxes are within the range indicated by the uncertainty bars. The model is not as successful with the observed seasonality of $\mathrm{H}$ fluxes (missing the springtime peak), which is a deficiency also found in deciduous forest simulations (Morgan Monroe State Forest) with the Community Land Model version 3.5 (CLM3.5) [Stöckli et al., 2008b].

[30] The GISS LSM is also quite skillful at simulating LE flues at Bondville, where the peak and timing of the simulated fluxes are in remarkable agreement with observations. The model performs well in terms of simulating $\mathrm{H}$ seasonality, although the magnitude of these fluxes tend to be lower than observations. At Niwot Ridge, the seasonality of modeled
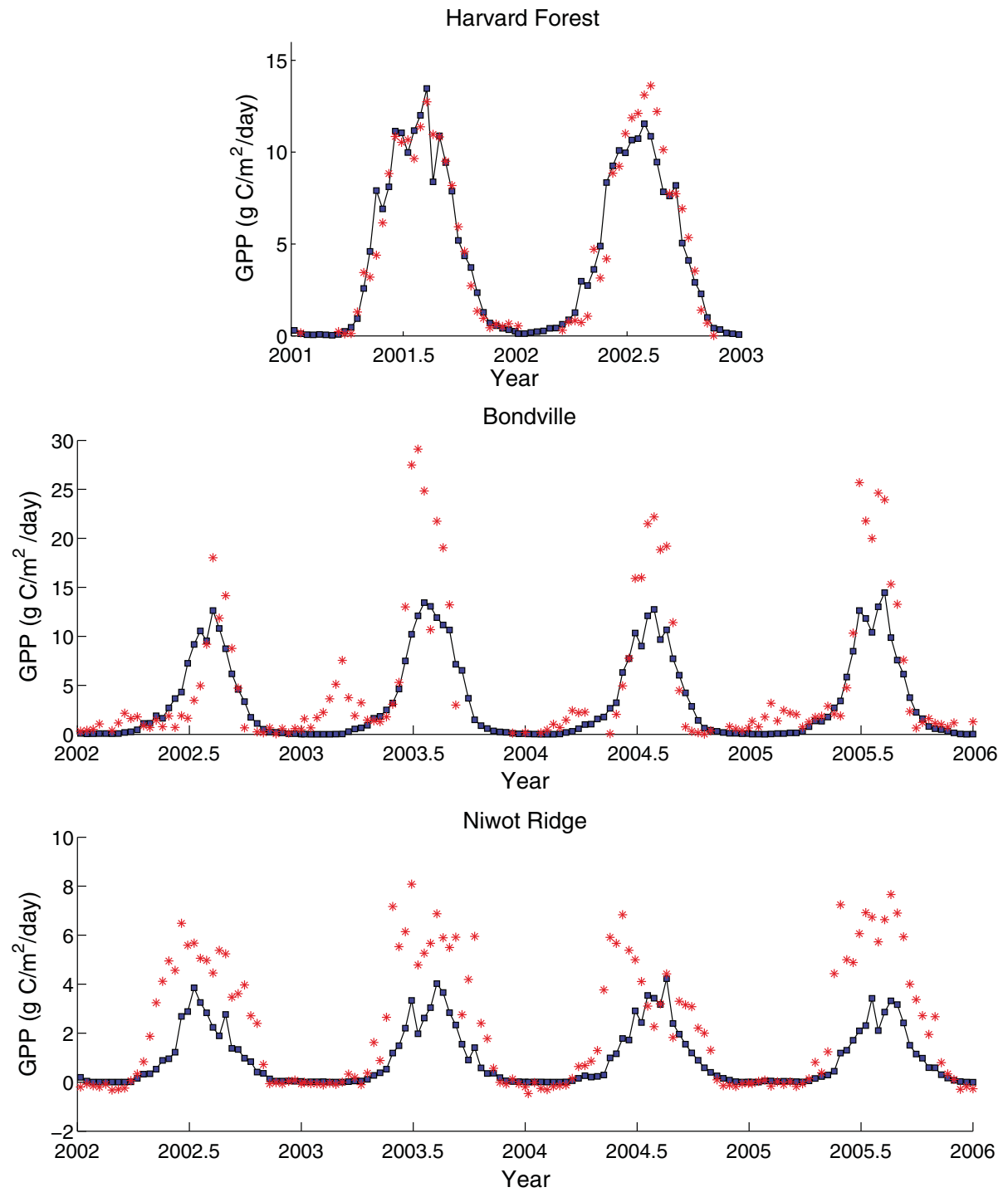

Figure 6. Comparison of model-predicted and level 4 observed GPP fluxes (10 day averages) at the three AmeriFlux sites. Model data are represented by a line with squares; observations are represented by stars. 

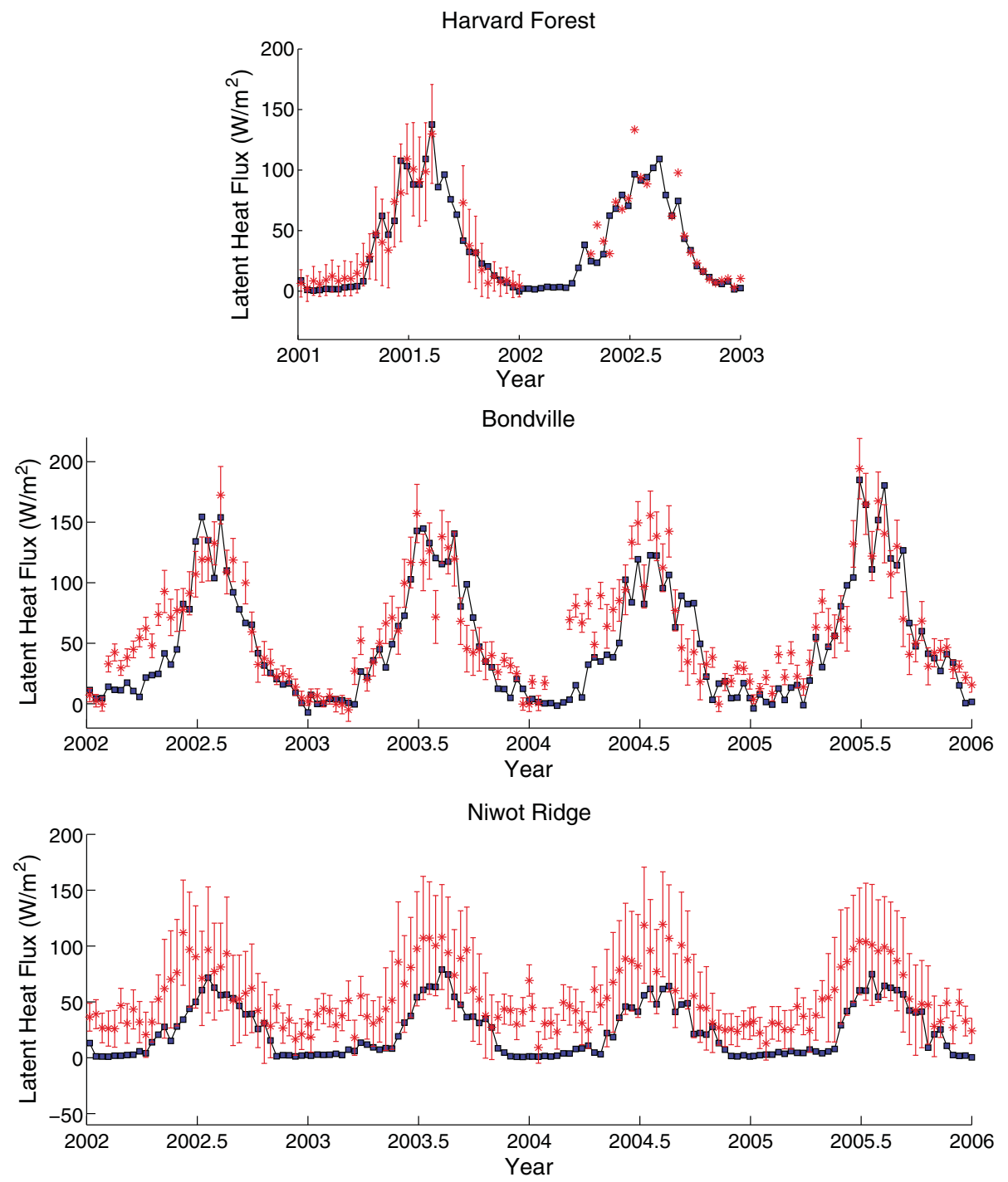

Figure 7. Comparison of model-predicted and level 2 observed latent heat fluxes (10 day averages) at the three AmeriFlux sites. Error bars represent the estimated (random and systematic) uncertainties associated with the observations. Model data are represented by a line with squares; observations are represented by stars. Note that for Harvard Forest, net radiation observations were not available for 2002, so these uncertainties were not estimated.

LE fluxes is in agreement with observations, but simulated LE fluxes are lower than observations. H fluxes are simulated quite well in terms of timing and magnitude.

[31] Part of the discrepancies in flux magnitudes can be attributed to the failure in energy balance closure, which we estimate using linear regression coefficients [e.g., Wilson et al., 2002]. The energy balance closure problem is most significant at both Bondville (slope: 0.64; intercept: $19 \mathrm{~W} / \mathrm{m}^{2}$ ) and Niwot Ridge (slope: 0.73 ; intercept: $13 \mathrm{~W} / \mathrm{m}^{2}$ ) and less problematic at Harvard Forest (slope: 0.83; intercept: $-3.9 \mathrm{~W} / \mathrm{m}^{2}$ ); ideal energy balance closure would have a slope of 1 and intercept of 0 [Wilson et al., 2002]. Deficiencies in model processes are also possible. For example, the wintertime LE underestimate suggests possible deficiencies in the snow evaporation/sublimation algorithm [Lynch-Stieglitz, 1994], given the persistent snow cover at this site during winter [Monson et al., 2005]. Growing season discrepancies may vary due to vegetation parameters, such as the water stress factor, that are not optimized for the vegetation at a particular AmeriFlux site.

[32] The main goal associated with this AmeriFlux evaluation is to determine whether the GISS LSM is capable of realistically simulating LE, H, and GPP fluxes. While there is room for improvement (as with all state-of-the-art models), the results here (Figures 6-8) demonstrate that in general, the GISS LSM skillfully simulates these dynamics in terms of timing and magnitude. We therefore have confidence in applying the model for the experiments described by Figure 5 .

\subsection{Experiments}

[33] The simulation results are presented for GPP, evapotranspiration (ET), and transpiration in Figures 9-11, respectively. In each, we present a four-paneled figure with box plots of the annual fluxes, the timing of the $50 \%$ cumulative 

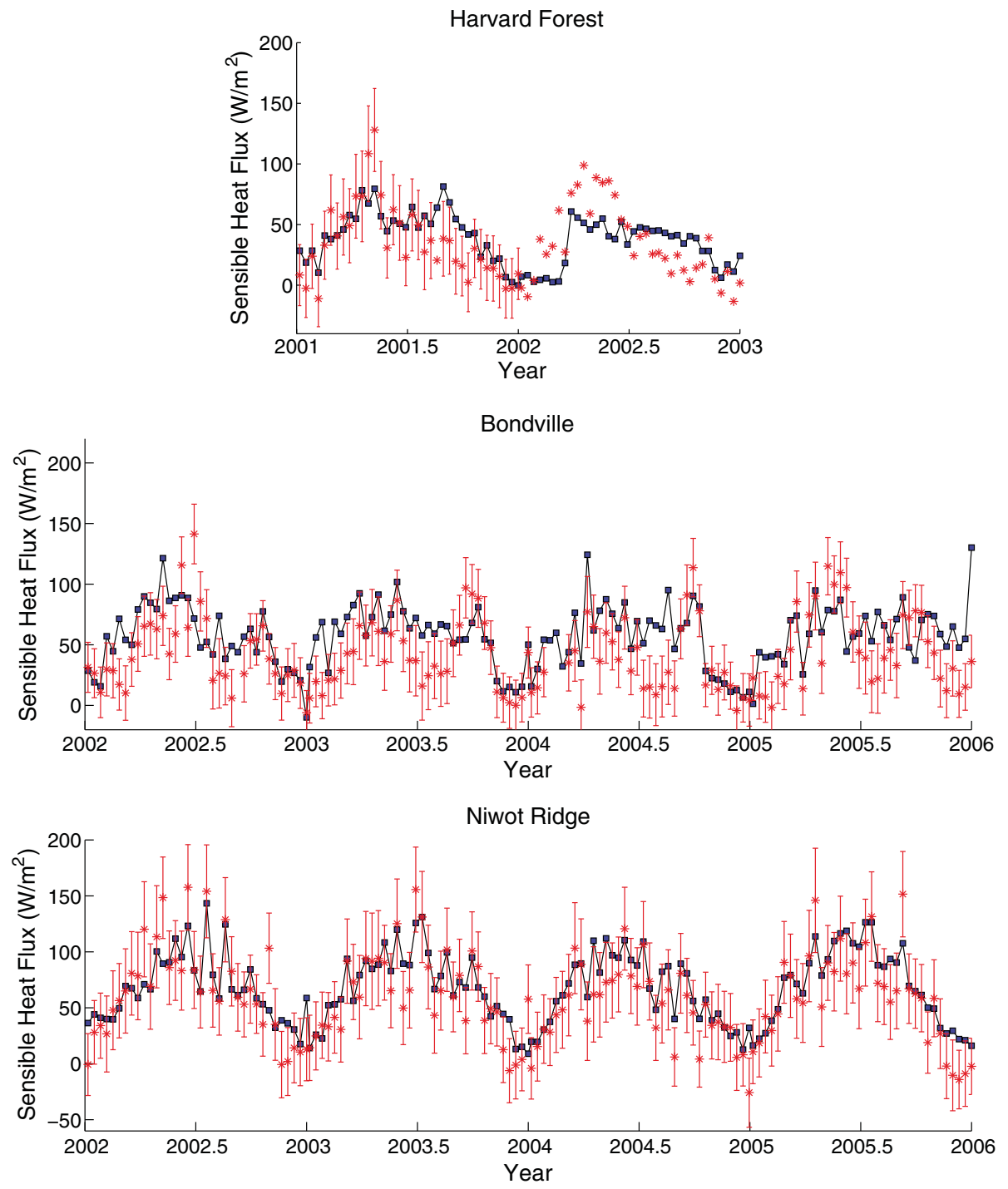

Figure 8. Comparison of model-predicted and level 2 observed sensible heat fluxes (10 day averages) at the three AmeriFlux sites. Error bars represent the estimated (random and systematic) uncertainties associated with the observations. Model data are represented by a line with squares; observations are represented by stars. Note that for Harvard Forest, net radiation observations were not available for 2002, so these uncertainties were not estimated.

annual flux, the value of the maximum pentad ( 5 day) flux, and the timing of this maximum pentad flux. As with standard box plots, the median is the central line and the 25 th and 75 th percentiles are the box edges. The whiskers extend to the lowest datum within 1.5 times the inter-quartile range (IQR) of the lower quartile and to the highest datum within 1.5 times the IQR of the upper quartile. The remaining data outside this range are plotted separately with markers. Model simulations with historical LAI and meteorological forcings are presented at the end of this section. Note that for all sites, time is measured from 1 January. Alternatively, we could present timing results based on the start of the water year (i.e., 1 October) at the western (W and FW) sites, but because the results turn out to be the same, we do not distinguish starting dates among the sites for clarity.

[34] Figure 9 presents the box plots for GPP at the four sites. We first note that vegetation productivity, as measured by total annual GPP, decreases moving from east to west (Figure 9a). At the sites where energy limits evapotranspiration (NE and S sites), differences in annual GPP are due primarily to the vegetation cover (i.e., forest versus crops). Reduced productivity by vegetation at the $\mathrm{W}$ and FW sites is due to the joint impacts of reduced vegetation cover and water availability. At all sites, LAI control (LAI_v) on the distribution of annual GPP is clearly larger than meteorological control (MET_v), as indicated by the broader range of values seen for the LAI_v averages. Strong LAI control at the $\mathrm{S}$ site stands out, $\overline{\mathrm{a}}$ consequence of the site's relatively large inter-annual variability in maximum growing season LAI (Figure 4b), which is related to year-to-year differences in crop distribution and production of soybean, maize, and cotton.

[35] We next consider the relative controls of LAI and meteorology on the temporal distribution of fluxes within a 
PUMA ET AL.: CONTROLS ON LAND-ATMOSPHERE FLUXES

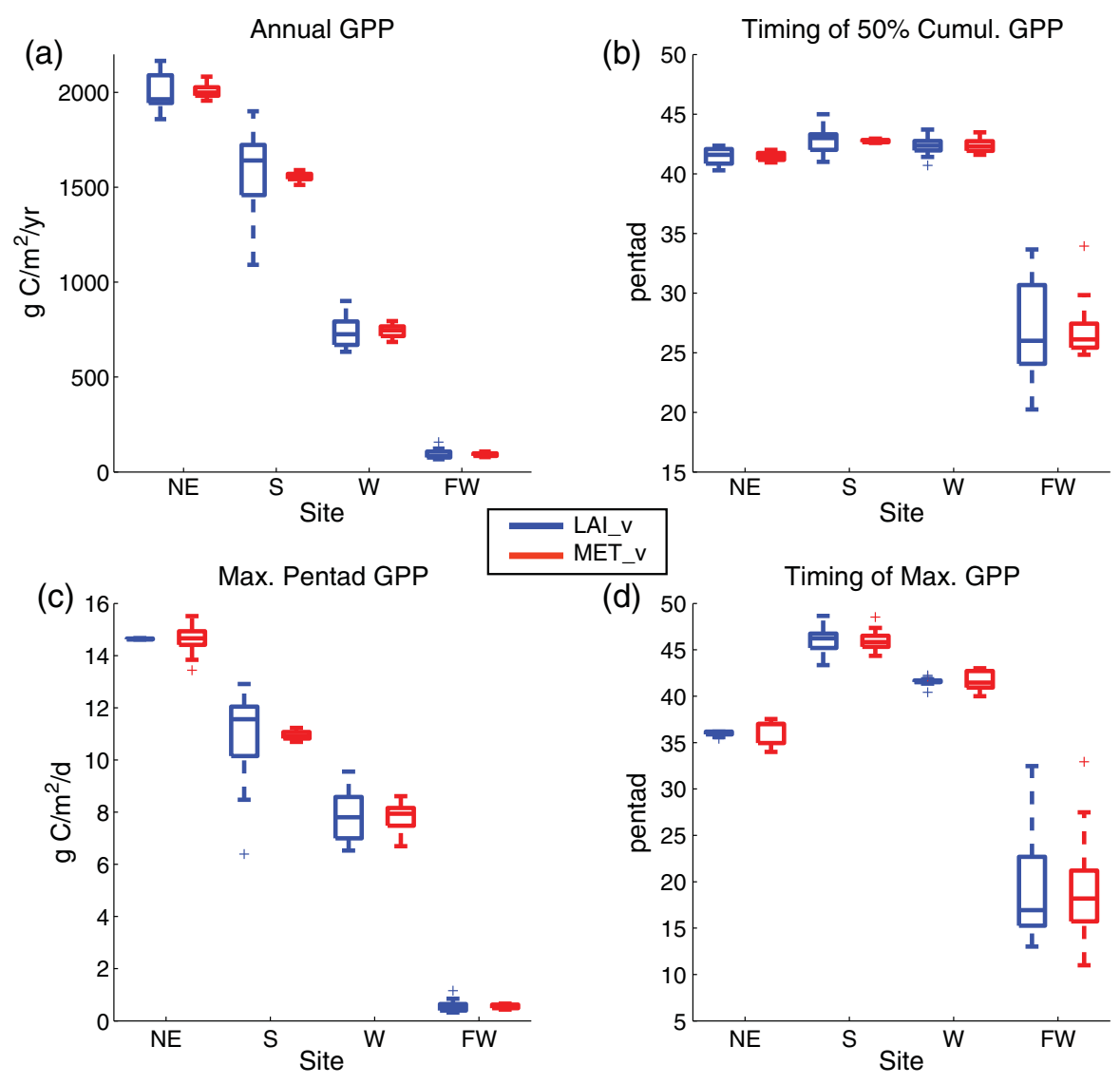

Figure 9. Box plots of gross primary productivity for the LAI and meteorological experiments: (a) annual values, (b) timing of the cumulative $50 \%$ of the annual flux, (c) maximum pentad flux, and (d) timing of the maximum (pentad) flux.

year using the timing of the cumulative $50 \%$ of the annual flux. The variability in this timing is relatively modest (i.e., $\mathrm{IQR} \approx 1$ pentad) except at the $\mathrm{FW}$ site $(\mathrm{IQR} \approx 7$ pentads for the LAI v case). Why is the variability in the timing so large at the $\overline{\mathrm{F} W}$ site (Figure 4)? First, it is clear from Figure 9 that the magnitude of GPP at the FW site is relatively small. Also, vegetation productivity at the site is intermittent, typically linked to periods of sufficient water availability. These intermittent periods of productivity are large enough to account for a substantial fraction of the annual total GPP. The LAI of the NE site shows variation in timing of spring green-up and autumn senescence (Figure 4a); this variation results in fairly strong control of LAI on GPP at the site (Figure 9a). At the $\mathrm{S}$ and $\mathrm{W}$ sites, substantial LAI control on GPP occurs due to variation not only in green-up and senescence timing but also in maximum LAI (Figures $4 \mathrm{~b}$ and $4 \mathrm{c}$, respectively).

[36] Moving beyond the annual timescale, we next look at the maximum pentad ( 5 day) GPP fluxes (Figure 9c) and the timing of these pentad fluxes (Figure 9d). The magnitude of these maximum pentad fluxes for the LAI_v decreases across sites moving from east to west, in analogy to the results for annual GPP. At the NE site, the maximum pentad flux is essentially a fixed value, a direct consequence of the fixed peak growing season LAI (Figure 4a). On the other hand, the maximum LAI at the S site does display substantial inter-annual variability (Figure 4b), which corresponds to significant LAI control on the maximum pentad GPP.
[37] The timing of the pentad GPP fluxes is presented in Figure 9d to show LAI and meteorological controls on peak growing season productivity. Even though the NE and $\mathrm{S}$ sites are in energy-controlled evaporative regimes, the relatively short timescale associated with the maximum pentad flux (compared to the 50\% cumulative flux) allows meteorological forcings to have a greater influence. As expected, LAI at the NE site has minimal control on maximum pentad flux timing, while LAI control at the S site is only slightly larger than the meteorological control. Interestingly, the meteorological control at the $\mathrm{W}$ site is dominant, while the influences of LAI and meteorological forcings on timing of the pentad GPP fluxes are comparable at the FW site.

[38] The most notable difference between GPP and ET is that meteorological variability exerts a larger control than LAI variability for all quantities in Figure 10. At the NE site, the lack of LAI control is a partial manifestation of LAI seasonality, where the maximum growing season LAI is essentially constant. At the $\mathrm{S}$ and $\mathrm{W}$ sites, LAI variability is not inconsequential, although meteorological effects are still larger for each quantity in Figure 10. The strongest relative ET control of meteorology occurs at the FW site, where bare soil coverage and the associated soil evaporation are substantial (19\% bare soil). Also, the site's small LAI values diminish any phenological influences on ET.

[39] LAI has the greatest relative control on annual ET at the S site (Figure 10a), which is linked to the relatively large year-to-year differences in LAI. LAI also influences ET 
PUMA ET AL.: CONTROLS ON LAND-ATMOSPHERE FLUXES
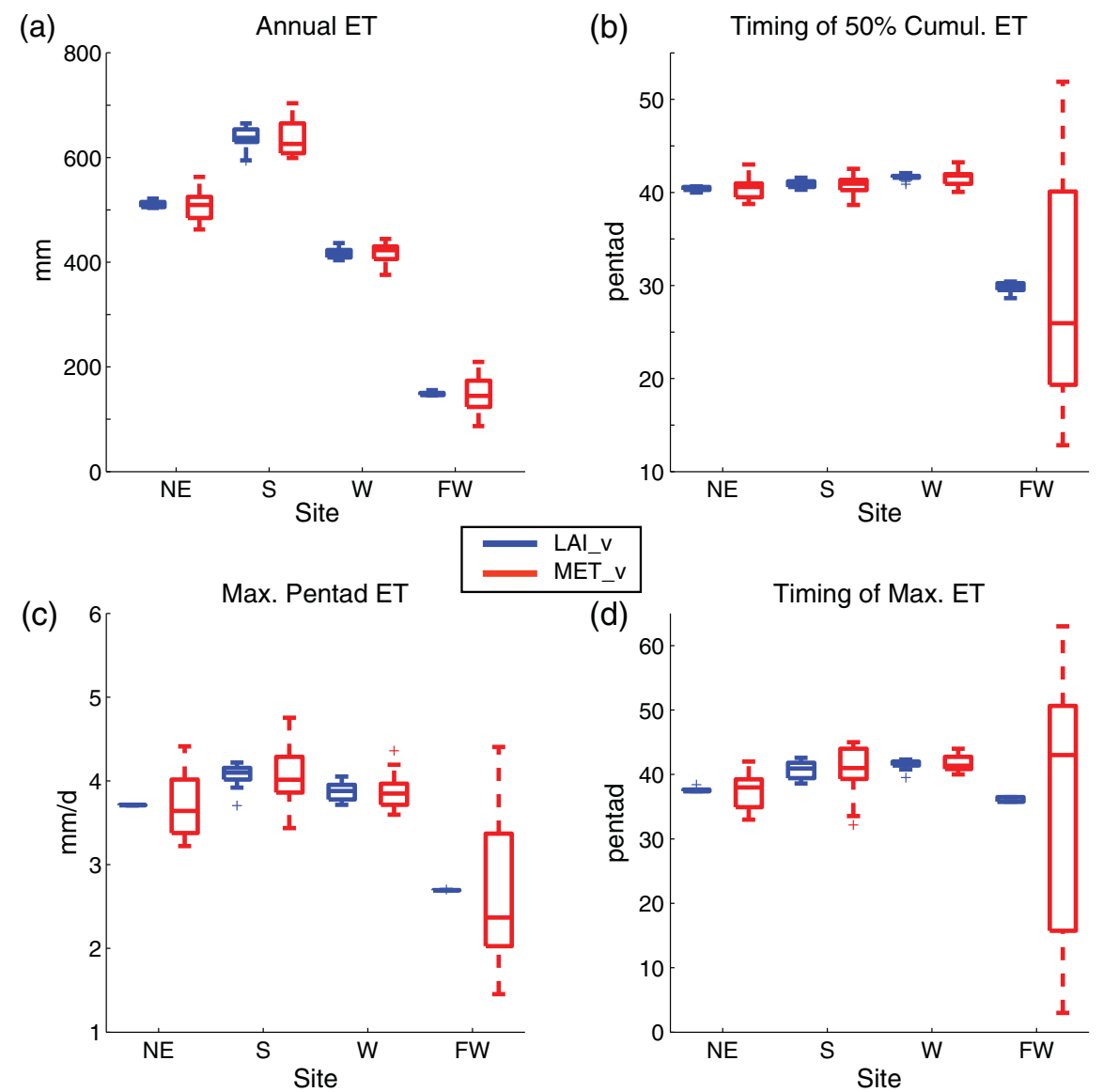

Figure 10. Box plots of evapotranspiration for the LAI and meteorological experiments: (a) annual values, (b) timing of the cumulative $50 \%$ of the annual flux, (c) maximum pentad flux, and (d) timing of the maximum (pentad) flux.

timing, where its strongest relative control on the timing of its $50 \%$ cumulative flux (Figure 10b) is at the $\mathrm{S}$ site and slightly less at the NE site. LAI exerts an important control on the cumulative flux timing at the $\mathrm{W}$ and FW sites (although meteorological forcings are still more influential). LAI control on the timing of its $50 \%$ cumulative flux (Figure 10b) is again strongest at the $\mathrm{S}$ site and slightly less at the NE site.

[40] The LAI influence on the maximum pentad flux and its timing (Figures 10c and 10d) does play a role at the S site, which has an energy-limited evaporative regime and significant inter-annual LAI variability. The NE site has no interannual variability in peak growing season LAI, while soil moisture controls at the FW site are extremely strong. Therefore, meteorological controls on the maximum pentad fluxes and their timing are dominant with LAI having a very small influence. The influence of LAI at the semiarid W site is slightly greater, because it is slightly wetter and has greater LAI inter-annual variability.

[41] Figure 11 separates out the impacts on transpiration, for which we find that neither LAI nor meteorological forcings have a consistently larger influence on all the plotted quantities. The relative control of LAI on annual transpiration becomes larger moving from the NE site to the FW site (Figure 11a) as does the maximum pentad transpiration (Figure 11c). The temporal distribution of transpiration within a year (Figure 11b) also shows comparable influences of LAI and atmospheric forcings, where meteorological controls are somewhat stronger, except at the FW site. Here the LAI_v experiment has a large IQR for LAI_v (6.2 pentads), which is interesting in the context of GPP (Figure 9b) and ET timing (Figure 10b). That is, while the importance of LAI is similar for transpiration and GPP timing, it is unimportant for ET timing. This result is explained by the fact that the average contribution of transpiration to total ET at this site is only $14 \%$. As for timing of the maximum transpiration flux, meteorological controls are most important at the energylimited sites, whereas LAI controls are more substantial at the FW site (Figure 11d).

[42] Surface and subsurface runoff are also relevant surface water fluxes. LAI variability potentially impacts surface runoff by modifying transpiration and canopy interception of precipitation. However, a box plot (not shown) of LAI and meteorological controls on the surface runoff fluxes and their timing reveals that LAI control is negligible relative to meteorological controls at all four sites. The same is true for subsurface runoff.

[43] Guillevic et al. [2002] point out that in real-world, moisture-limited regimes, periods of lower precipitation are often associated with periods of lower vegetation density and vice versa. To assess whether our model reproduces this expected behavior, we compare in Figure 12 the standard deviation of GPP, ET, and transpiration for the 17 realizations with the actual historical combinations of 
PUMA ET AL.: CONTROLS ON LAND-ATMOSPHERE FLUXES
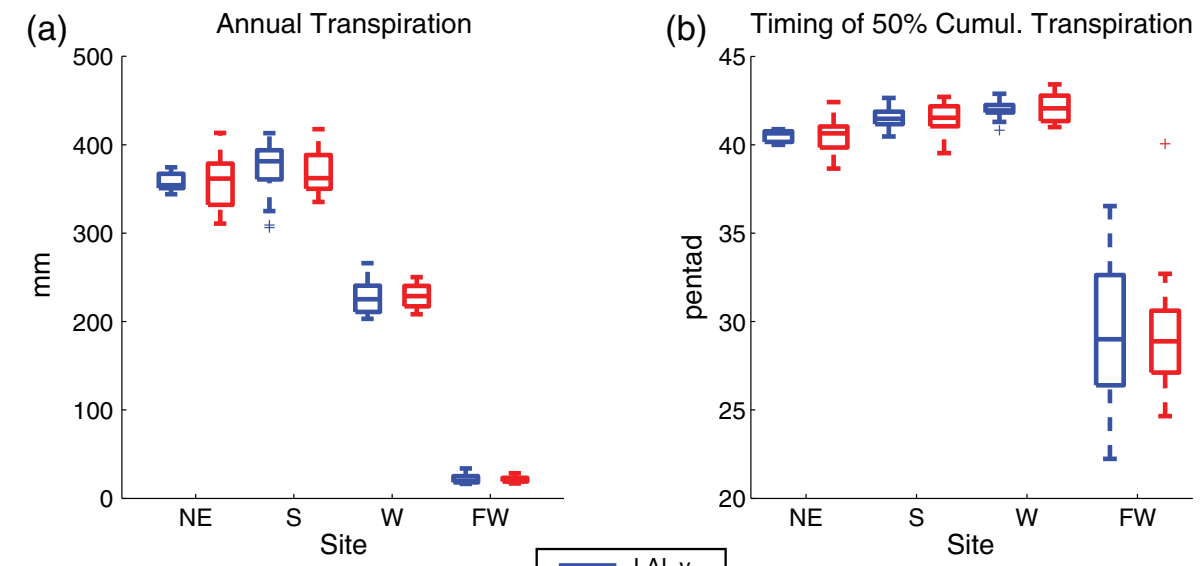

(c)

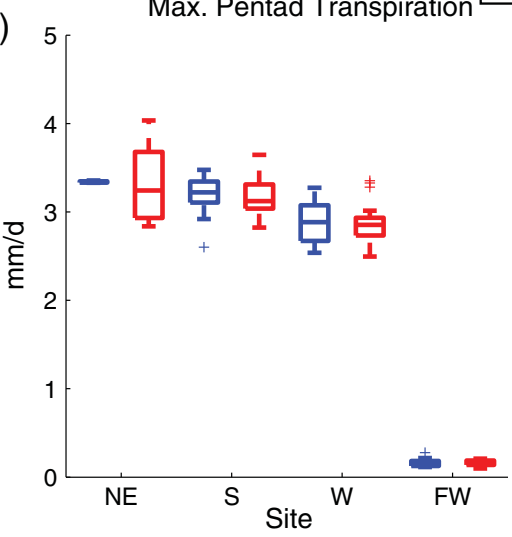

(d)
Timing of Max. Transpiration

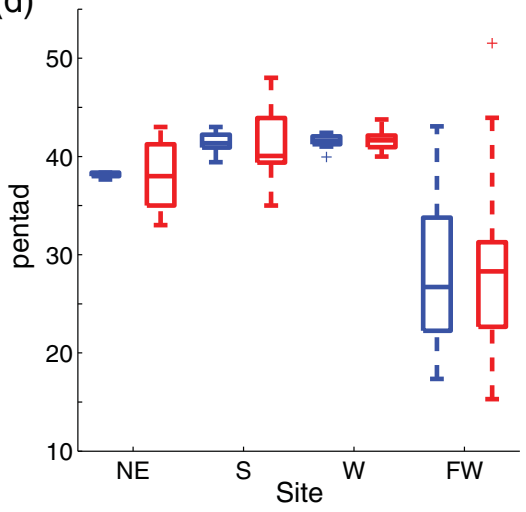

Figure 11. Box plots of transpiration for the LAI and meteorological experiments: (a) annual values, (b) timing of the cumulative $50 \%$ of the annual flux, (c) maximum pentad flux, and (d) timing of the maximum (pentad) flux.

LAI and meteorological forcings ( $\left.\sigma_{X \text {,actual }}\right)$ to that obtained for the entire set of 289 realizations $\left(\sigma_{X \text {,all }}\right)$. If $\sigma_{X \text {,actual }}$ exceeds $\sigma_{X, \text { all }}$, then it provides evidence that correlations in nature between LAI and atmospheric variables have a compounding effect on the extremes of carbon and water fluxes.

[44] Figure 12 (top) presents the standard deviation comparison for annual GPP, which shows that $\sigma_{\mathrm{GPP} \text {,actual }}$ exceeds $\sigma_{\mathrm{GPP}, \text { all }}$ at all sites. In middle panel, we find that $\sigma_{\mathrm{ET} \text {,actual }}$ exceeds $\sigma_{\mathrm{ET} \text {,all }}$ at three sites, with the $\mathrm{W}$ site being the exception. The bottom panel shows transpiration results. For reference, the percentages of transpiration in annual ET at the NE, S, W, and FW sites are approximately $48 \%, 42 \%, 42 \%$, and $25 \%$, respectively. We find that the standard deviation for the actual forcings is larger than the whole-realization standard deviation except for ET at the $\mathrm{W}$ site and transpiration at the $\mathrm{S}$ site, although the differences are not statistically significant based on a twosided Student's $t$ test. (This is not surprising given the small number of actual forcing years.) Then, for the most part, our results support the idea that correlations in LAI and meteorological anomalies help exacerbate extremes in surface fluxes. This is particularly indicated for the NE and FW sites, for which an analysis of the histograms of the fluxes (not shown) reveal a shift in the distribution of the fluxes toward the extremes.

\section{Discussion and Conclusions}

[45] The simulation of vegetation in climate models has been the focus of considerable model development and research efforts. What remains unclear is the importance of LAI variability relative to that of atmospheric variables for different climate regimes and vegetation. As modelers make decisions with regard to model complexity for representing land and vegetation dynamics, a clearer understanding of how LAI impacts land-atmosphere interactions is essential. We find that the relative importance of LAI phenology varies substantially depending on the flux of interest, the characteristics of LAI variability, and the climate regime. Our analyses indicate that relative to meteorological variables, LAI has a dominant control on gross primary productivity, a comparable (but smaller) influence on transpiration, a weaker influence on evapotranspiration, and a negligible impact on runoff.

[46] GCMs use an energy balance approach to compute evapotranspiration and sensible heat fluxes; in this approach, surface-to-air temperature and humidity differences are key driving forces controlling these fluxes [e.g., Cornwell and Harvey, 2007]. In comparison, GPP fluxes are modeled through a dependence on relative humidity and leaf surface $\mathrm{CO}_{2}$ concentrations as well as through environmental stress factors that affect the vegetation's photosynthetic capacity. 

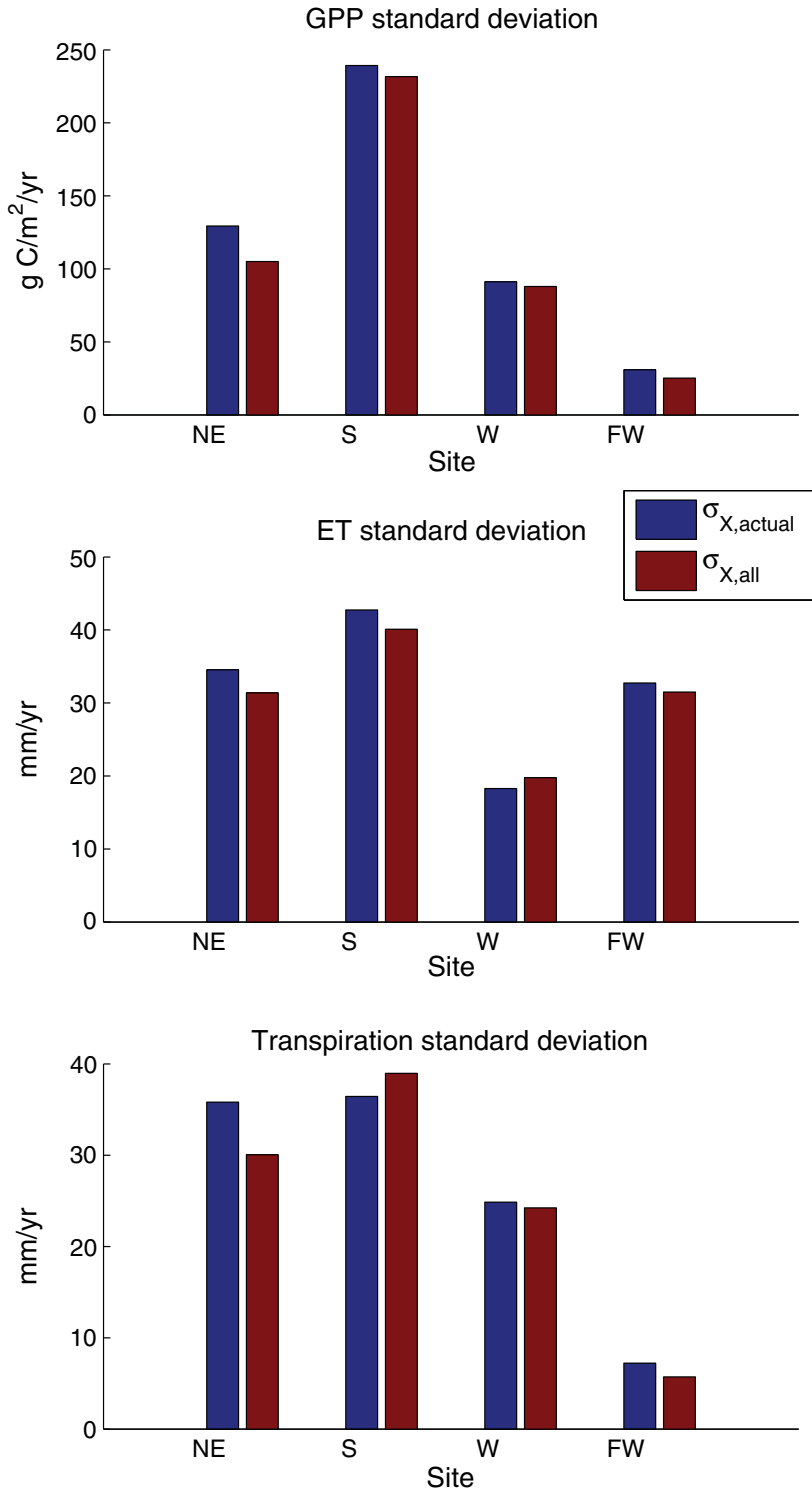

Figure 12. Standard deviation of actual LAI and meteorological forcings $\left(\boldsymbol{\sigma}_{\boldsymbol{X}}\right.$,actual $)$ compared with the standard deviation of all simulations $\left(\boldsymbol{\sigma}_{\boldsymbol{X}}\right.$,all $)$ for GPP, ET, and transpiration.

Although GPP and the transpiration component of ET are coupled through a common canopy conductance term, meteorological controls on these fluxes are not equivalent. We see, for example, that at the NE site, LAI has a dominant control on annual GPP, while meteorology has the dominant control on annual transpiration. This difference is a consequence of the complex interplay of meteorology, LAI, and vegetation biophysical properties at the site.

[47] The modulating effects of climate regime and LAI variations on the relative control of LAI and meteorology depend on the flux and timescale of interest. In terms of climate effects, evaporative regime (as estimated by evaporative fraction) is useful as a basic indicator of LAI control on annual and maximum pentad GPP; LAI at energy-limited sites tends to exhibit greater control than at the moisturelimited sites. Other characteristics of LAI (e.g., seasonality and inter-annual variability), however, also appear to be important modulators of LAI control on surface fluxes. This is clearly demonstrated at the NE site, where the maximum growing season LAI is constant from year to year, thereby reducing LAI control on GPP (Figures 9a and 9c). Evaporative regime is also valuable for assessing the relative LAI control on annual and maximum pentad transpiration, where relative LAI control is somewhat less at energy-limited sites and greater at moisture-limited sites (Figures 11a and 11c). For total ET, LAI has much less impact on variation in ET than does meteorology. At shorter timescales that are important for the timing of fluxes, the modulating effects of climate regime and LAI are unclear. One exception is at the FW site, where precipitation variability is very large and, consequently, meteorological controls dominate ET timing.

[48] The strong control of LAI on gross primary productivity points to the need to have accurate representation of LAI variability within climate models. Climate modelers focused on the carbon cycle therefore need to select approaches for representing LAI phenology, whether prescribed or prognostically computed, that realistically capture inter-annual LAI variability. In particular, two characteristics of the LAI seasonal cycle affect the extent of LAI control: variability in maximum LAI and in the timing of spring green-up and autumn senescence. Vegetation types [e.g., DeFries et al., 1995] that exhibit significant inter-annual variability in both green-up time and maximum growing season LAI are especially important to represent accurately. Efforts to assimilate remotely sensed phenology data [e.g., Stöckli et al., 2008a, 2011] should concentrate on improving phenological estimates of vegetation with these characteristics.

[49] While the interplay between LAI and carbon fluxes is particularly important in relation to global carbon emissions, the connection between LAI and water fluxes is more relevant to the simulation of regional climate in GCMs. Pitman et al. [2012], in a review of processes needed to improve regional climate representation, identified crop phenology as one potentially important factor. Although our findings show that the controls of LAI phenology are not as important for evapotranspiration as they are for transpiration, researchers have highlighted the importance of realistic partitioning of evapotranspiration into transpiration, soil evaporation, and canopy evaporation within GCMs [e.g., Lawrence et al., 2007]. Importantly, we find that at sites with the greatest variability in LAI (S and W sites), phenology has a significant control on evapotranspiration timing. Such timing is important as it can affect the seasonality of model-generated precipitation and other atmospheric variables.

[50] We find that the correlations between LAI and atmospheric variables do impact the extremes of carbon and water fluxes, especially at two of our sites (NE and FW sites). This finding suggests that the representation of LAI correlations with atmospheric variables is needed, highlighting the potential value of dynamical vegetation modeling. This is particularly relevant given that climate models are increasingly needed for investigations of, for example, temperature and precipitation extremes in a changing climate.

[51] Our results must be qualified by several limitations of our experimental design. The sensitivities shown are for a specific land model and would presumably be somewhat different for other land models; in this sense, we emphasize our first-order findings rather than quantitative details. Also, only 17 years of data were available for the statistical analyses. These limitations present opportunities for additional 
research with, for example, a recently released 30 year LAI data set (http://cliveg.bu.edu/modismisr/index.html) used in a coordinated experiment with several of the latest dynamical models.

[52] Acknowledgments. The authors gratefully acknowledge funding for Interdisciplinary Global Change Research under NASA cooperative agreement NNX08AJ75A supported by the NASA Climate and Earth Observing Program. The Collection 4 MODIS LAI (MOD15A2) data were obtained through the online Data Pool at the NASA Land Processes Distributed Active Archive Center (LP DAAC, http://lpdaac.usgs.gov/get data). Meteorological driver and validation data were collected and prepared by the individual AmeriFlux site principal investigators and their teams, so we would like to extend our thanks to J. William Munger (Harvard Forest), Tilden Meyers (Bondville), and Peter Blanken and Russell Monson (Niwo Ridge). We also recognize funding of AmeriFlux sites by the Department of Energy's Climate and Environmental Sciences Division within the Office of Biological and Environmental Research. Finally, we would like to thank the anonymous reviewers, whose comments greatly improved this paper.

\section{References}

Abramopoulos, F., C. Rosenzweig, and B. Choudhury (1988), Improved ground hydrology calculations for global climate models (GCMs): Soil water movement and evapotranspiration, J. Clim., 1, 921-941.

Aleinov, I., and G. A. Schmidt (2006), Water isotopes in the GISS ModelE land surface scheme, Global Planet. Change, 51(1-2), 108-120.

Alessandri, A., S. Gualdi, J. Polcher, and A. Navarra (2007), Effects of land surface-vegetation on the boreal summer surface climate of a GCM, J. Clim., 20(2), 255-278.

Alton, P., L. Mercado, and P. North (2007), A sensitivity analysis of the land-surface scheme JULES conducted for three forest biomes: Biophysical parameters, model processes, and meteorological driving data, Global Biogeochem. Cycles, 20, GB1008, doi:10.1029/2005GB002653.

Baldocchi, D., et al. (2001), Fluxnet: A new tool to study the temporal and spatial variability of ecosystem-scale carbon dioxide, water vapor, and energy flux densities, Bull. Am. Meteorol. Soc., 82(11), 2415-2434.

Ball, J. T., I. E. Woodrow, and J. A. Berry (1987), A model predicting stomatal conductance and its application to the control of photosynthesis under different environmental conditions, in Progress in Photosynthesis, edited by I. Biggins, pp. 221-224, Martinus Nijhoff, Zoetermeer, Netherlands.

Bonan, G. B., and S. Levis (2006), Evaluating aspects of the community land and atmosphere models (CLM3 and CAM3) using a dynamic global vegetation model, J. Clim., 19(11), 2290-2301.

Bonan, G. B., S. Levis, L. Kergoat, and K. W. Oleson (2002), Landscapes as patches of plant functional types: An integrating concept for climate and ecosystem models, Global Biogeochem. Cycles, 16(2), 1021, doi:10.1029/ 2000GB001360

Bonan, G. B., S. Levis, S. Sitch, M. Vertenstein, and K. W. Oleson (2003), A dynamic global vegetation model for use with climate models: Concepts and description of simulated vegetation dynamics, Global Change Biol., 9(11), 1543-1566.

Bowman, A., and A. Azzalini (1997), Applied Smoothing Techniques for Data Analysis: The Kernel Approach With S-Plus Illustrations, Oxford Stat. Sci. Ser., vol. 18, Oxford Univ. Press, New York.

Buermann, W., J. Dong, X. Zeng, R. Myneni, and R. Dickinson (2001), Evaluation of the utility of satellite-based vegetation leaf area index data for climate simulations, J. Clim., 14(17), 3536-3550.

Cook, B. I., M. J. Puma, and N. Y. Krakauer (2011), Irrigation induced surface cooling in the context of modern and increased greenhouse gas forcing, Clim. Dyn., 37(7-8), 1587-1600.

Cornwell, A. D., and L. D. D. Harvey (2007), Soil moisture: A residua problem underlying AGCMs, Clim. Change, 84, 310-336.

DeFries, R., and M. Hansen (2010), ISLSCP II University of Maryland Global Land Cover Classifications, 1992-1993, in ISLSCP Initiative II Collection, edited by F. G. Hall et al., https://daac.ornl.gov/ISLSCP II/ guides/umd_landcover_xdeg.html, Oak Ridge Natl. Lab. Distributed Active Arch. Cent., Oāk Ridge, Tenn.

DeFries, R., et al. (1995), Mapping the land surface for global atmospherebiosphere models: Toward continuous distributions of vegetation's functional properties, J. Geophys. Res., 100(D10), 20,867-20,882.

Dirmeyer, P., X. Gao, G. Zhao, Z. Guo, T. Oki, and N. Hanasaki (2006), GSWP2: Multimodel analysis and implications for our perception of the land surface, Bull. Am. Meteorol. Soc., 87, 1381-1397 doi:10.1175/ BAMS-87-10-1381.

Falge, E., et al. (2002), Seasonality of ecosystem respiration and gross primary production as derived from FLUXNET measurements, Agric. For. Meteorol., 113(1), 53-74.
Farquhar, G. D., S. von Caemmerer, and J. A. Berry (1980), A biochemical model of photosynthetic $\mathrm{CO}_{2}$ assimilation in leaves of $\mathrm{C}_{3}$ species, Planta, 149, 78-90.

Farquhar, G., et al. (1982), Modelling of photosynthetic response to environmental conditions, Encycl. Plant Physiol., New Ser., 12, 549-587.

Foley, J. A., I. C. Prentice, N. Ramankutty, S. Levis, D. Pollard, S. Sitch, and A. Haxeltine (1996), An integrated biosphere model of land surface processes, terrestrial carbon balance, and vegetation dynamics, Global Biogeochem. Cycles, 10(4), 603-628.

Friedlingstein, P., et al. (2006), Climate-carbon cycle feedback analysis: Results from the (CMIP)-M-4 model intercomparison, J. Clim., 19(14), 3337-3353.

Friend, A. D., and N. Y. Kiang (2005), Land surface model development for the GISS GCM: Effects of improved canopy physiology on simulated climate, J. Clim., 18(15), 2883-2902.

Friend, A. D., et al. (2007), FLUXNET and modelling the global carbon cycle, Global Change Biol., 13(3), 610-633.

Ganguly, S., M. Schull, A. Samanta, N. Shabanov, C. Milesi, R. Nemani, Y. Knyazikhin, and R. Myneni (2008), Generating vegetation leaf area index Earth system data record from multiple sensors. Part 1: Theory, Remote Sens. Environ., 112(12), 4333-4343.

Grünwald, T., and C. Bernhofer (2007), A decade of carbon, water and energy flux measurements of an old spruce forest at the Anchor Station Tharandt, Tellus, Ser. B, 59(3), 387-396.

Guillevic, P., R. Koster, M. Suarez, L. Bounoua, G. Collatz, S. Los, and S. Mahanama (2002), Influence of the interannual variability of vegetation on the surface energy balance-A global sensitivity study, J. Hydrometeorol., 3(6), 617-629.

Guo, Z., et al. (2006), GLACE: The Global Land-Atmosphere Coupling Experiment. Part II: Analysis, J. Hydrometeorol., 7(4), 611-625, doi:10.1175/JHM511.1.

Hagen, S., B. Braswell, E. Linder, S. Frolking, A. Richardson, and D. Hollinger (2006), Statistical uncertainty of eddy flux-based estimates of gross ecosystem carbon exchange at Howland Forest, Maine, J. Geophys. Res., 111, D08S03, doi:10.1029/2005JD006154.

Hansen, J. E., et al. (2007), Climate simulations for 1880-2003 with GISS modelE, Clim. Dyn., 29(7-8), 661-696.

Hasler, N., D. Werth, and R. Avissar (2009), Effects of tropical deforestation on global hydroclimate: A multimodel ensemble analysis, J. Clim., 22(5), 1124-1141.

Henderson-Sellers, A., A. Pitman, P. Love, P. Irannejad, and T. Chen (1995), The project for intercomparison of land surface parameterization schemes (PILPS): Phases 2 and 3, Bull. Am. Meteorol. Soc., 76(4), 489-503.

Jiménez, C., et al. (2011), Global intercomparison of 12 land surface heat flux estimates, J. Geophys. Res., 116, D02102, doi:10.1029/2010JD014545.

Kang, H., Y. Xue, and G. Collatz (2007), Impact assessment of satellitederived leaf area index datasets using a general circulation model, J. Clim., 20(6), 993-1015.

Kim, Y., and G. Wang (2005), Modeling seasonal vegetation variation and its validation against Moderate Resolution Imaging Spectroradiometer (MODIS) observations over North America, J. Geophys. Res., 110, D04106, doi:10.1029/2004JD005436.

Kim, Y., and G. Wang (2007), Impact of vegetation feedback on the response of precipitation to antecedent soil moisture anomalies over North America, J. Hydrometeorol., 8(3), 534-550, doi:10.1175/JHM612.1.

Koster, R. D., and M. J. Suarez (1992), Modeling the land surface boundary in climate models as a composite of independent vegetation stands, J. Geophys. Res., 97(D3), 2697-2715.

Krakauer, N. Y., B. I. Cook, and M. J. Puma (2010), Contribution of soil moisture feedback to hydroclimatic variability, Hydrol. Earth Syst. Sci., 14(3), 505-520.

Kramer, K., I. Leinonen, and D. Loustau (2000), The importance of phenology for the evaluation of impact of climate change on growth of boreal temperate and Mediterranean forests ecosystems: An overview, Int. J. Biometeorol., 44(2), 67-75.

Krinner, G., N. Viovy, N. de Noblet-Ducoudré, J. Ogée, J. Polcher, P. Friedlingstein, P. Ciais, S. Sitch, and I. Prentice (2005), A dynamic global vegetation model for studies of the coupled atmosphere-biosphere system, Global Biogeochem. Cycles, 19, GB1015, doi:10.1029/2003GB002199.

Kucharik, C., C. Barford, M. Maayar, S. Wofsy, R. Monson, and D. Baldocchi (2006), A multiyear evaluation of a dynamic global vegetation model at three AmeriFlux forest sites: Vegetation structure, phenology, soil temperature, and $\mathrm{CO}_{2}$ and $\mathrm{H}_{2} \mathrm{O}$ vapor exchange, Ecol. Modell., 196(1-2), 1-31.

Lawrence, D. M., P. E. Thornton, K. W. Oleson, and G. B. Bonan (2007), The partitioning of evapotranspiration into transpiration, soil evaporation, and canopy evaporation in a GCM: Impacts on land-atmosphere interaction, J. Hydrometeorol., 8(4), 862-880.

Lawrence, P., and T. Chase (2007), Representing a new MODIS consistent land surface in the Community Land Model (CLM 3.0), J. Geophys. Res., 112, G01023, doi:10.1029/2006JG000168. 
Li, H., J. Sheffield, and E. Wood (2010), Bias correction of monthly precipitation and temperature fields from Intergovernmental Panel on Climate Change AR4 models using equidistant quantile matching, J. Geophys. Res., 115, D10101, doi:10.1029/2009JD012882.

Liu, Q., L. Gu, R. Dickinson, Y. Tian, L. Zhou, and W. Post (2008), Assimilation of satellite reflectance data into a dynamical leaf model to infer seasonally varying leaf areas for climate and carbon models, J. Geophys. Res., 113, D19113, doi:10.1029/2007JD009645.

Lu, L., and W. Shuttleworth (2002), Incorporating NDVI-derived LAI into the climate version of RAMS and its impact on regional climate, J. Hydrometeorol., 3(3), 347-362.

Lynch-Stieglitz, M. (1994), The development and validation of a simple snow model for the GISS GCM, J. Clim., 7(12), 1842-1855.

Matthews, E. (1984), Prescription of land-surface boundary conditions in GISS GCM II: A simple method based on fine-resolution data bases, NASA Tech. Memo, TM-86096, 20pp.

Meyers, T., and S. Hollinger (2004), An assessment of storage terms in the surface energy balance of maize and soybean, Agric. For. Meteorol., 125 (1), 105-115.

Monson, R., A. Turnipseed, J. Sparks, P. Harley, L. Scott-Denton, K. Sparks, and T. Huxman (2002), Carbon sequestration in a highelevation, subalpine forest, Global Change Biol., 8(5), 459-478.

Monson, R., J. Sparks, T. Rosenstiel, L. Scott-Denton, T. Huxman, P. Harley, A. Turnipseed, S. Burns, B. Backlund, and J. Hu (2005), Climatic influences on net ecosystem $\mathrm{CO}_{2}$ exchange during the transition from wintertime carbon source to springtime carbon sink in a highelevation, subalpine forest, Oecologia, 146(1), 130-147.

Morisette, J., et al. (2008), Tracking the rhythm of the seasons in the face of global change: Phenological research in the 21 st century, Front. Ecol. Environ., 7(5), 253-260.

Muraoka, H., N. Saigusa, K. Nasahara, H. Noda, J. Yoshino, T. Saitoh, S. Nagai, S. Murayama, and H. Koizumi (2010), Effects of seasonal and interannual variations in leaf photosynthesis and canopy leaf area index on gross primary production of a cool-temperate deciduous broadleaf forest in Takayama, Japan, J. Plant Res., 123(4), 563-576.

Noblet-Ducoudré, N., et al. (2012), Determining robust impacts of land-use induced land-cover changes on surface climate over North America and Eurasia: Results from the first set of LUCID experiments, J. Clim., 25 (9), 3261-3281.

Oak Ridge National Laboratory Distributed Active Archive Center (2011), MODIS subsetted land products, collection 5, technical report, Oak Ridge, Tenn. [Available at http://daac.ornl.gov/modis/modis.html.]

Piao, S., P. Friedlingstein, P. Ciais, N. Viovy, and J. Demarty (2007), Growing season extension and its impact on terrestrial carbon cycle in the Northern Hemisphere over the past 2 decades, Global Biogeochem. Cycles, 21, GB3018, doi:10.1029/2006GB002888.

Pitman, A., F. Avila, G. Abramowitz, Y. Wang, S. Phipps, and N. de Noblet-Ducoudré (2011), Importance of background climate in determining impact of land-cover change on regional climate, Nat. Clim. Change, $1,472-475$

Pitman, A., A. Arneth, and L. Ganzeveld (2012), Regionalizing global climate models, Int. J. Climatol., 32, 321-337.

Puma, M. J., and B. I. Cook (2010), Effects of irrigation on global climate during the 20th century, J. Geophys. Res., 115, D16120, doi:10.1029/ 2010JD014122.

Quillet, A., C. Peng, and M. Garneau (2010), Toward dynamic global vegetation models for simulating vegetation-climate interactions and feedbacks: Recent developments, limitations, and future challenges, Environ. Rev., 18, 333-353.

Reichstein, M., et al. (2005), On the separation of net ecosystem exchange into assimilation and ecosystem respiration: Review and improved algorithm, Global Change Biol., 11(9), 1424-1439.

Richardson, A., et al. (2006), A multi-site analysis of random error in towerbased measurements of carbon and energy fluxes, Agric. For. Meteorol., 136(1), 1-18.

Richardson, A., D. Hollinger, J. Aber, S. Ollinger, and B. Braswell (2007), Environmental variation is directly responsible for short-but not longterm variation in forest-atmosphere carbon exchange, Global Change Biol., 13(4), 788-803.
Richardson, A., et al. (2010), Influence of spring and autumn phenological transitions on forest ecosystem productivity, Philos. Trans. R. Soc. B, 365(1555), 3227-3246.

Rosenzweig, C., and F. Abramopoulos (1997), Land-surface model development for the GISS GCM, J. Clim., 10, 2040-2054.

Schmid, H., H. Su, C. Vogel, and P. Curtis (2003), Ecosystem-atmosphere exchange of carbon dioxide over a mixed hardwood forest in northern lower Michigan, J. Geophys. Res., 108(D14), 4417, doi:10.1029/2002JD003011.

Schmidt, G. A., et al. (2006), Present-day atmospheric simulations using GISS ModelE: Comparison to in situ, satellite, and reanalysis data, J. Clim., 19(2), 153-192.

Scholes, R. J., and E. Brown de Colstoun (2011), ISLSCP II global gridded soil characteristics, in ISLSCP Initiative II Collection, edited by F. G. Hall et al., https://daac.ornl.gov/ISLSCP_II/guides/islscp2 soils_1deg.html, Oak Ridge Natl. Lab. Distributed Active Arch. Cent., Oak Ridge, Tenn.

Sheffield, J., G. Goteti, and E. F. Wood (2006), Development of a 50-year high-resolution global dataset of meteorological forcings for land surface modeling, J. Clim., 19(13), 3088-3111.

Shevliakova, E., S. Pacala, S. Malyshev, G. Hurtt, P. Milly, J. Caspersen, L. Sentman, J. Fisk, C. Wirth, and C. Crevoisier (2009), Carbon cycling under 300 years of land use change: Importance of the secondary vegetation sink, Global Biogeochem. Cycles, 23, GB2022, doi:10.1029/2007GB003176.

Sietse, O. (2010), ISLSCP II FASIR-adjusted NDVI Biophysical Parameter Fields, 1982-1998, in ISLSCP Initiative II Collection, edited by F. G. Hall et al., https://daac.ornl.gov/ISLSCP_II/guides/fasir_biophys monthly xdeg.html,Oak Ridge Natl. Lab. Distributed Active Arch. Cent., Oak Ridge, Tenn.

Sitch, S., et al. (2003), Evaluation of ecosystem dynamics, plant geography and terrestrial carbon cycling in the LPJ dynamic global vegetation model, Global Change Biol., 9(2), 161-185.

Spitters, C. J. T. (1986), Separating the diffuse and direct component of global radiation and its implication for modeling canopy photosynthesis. Part II. Calculation of canopy photosynthesis, Agric. For. Meteorol., $38,231-242$.

Stöckli, R., T. Rutishauser, D. Dragoni, J. O'Keefe, P. E. Thornton, M. Jolly, L. Lu, and A. S. Denning (2008a), Remote sensing data assimilation for a prognostic phenology model, J. Geophys. Res., 113, G04021, doi:10.1029/2008JG000781.

Stöckli, R., D. M. Lawrence, G.-Y. Niu, K. W. Oleson, P. E. Thornton, Z.-L. Yang, G. B. Bonan, A. S. Denning, and S. W. Running (2008b), Use of FLUXNET in the community land model development, J. Geophys. Res., 113, G01025, doi:10.1029/2007JG000562.

Stöckli, R., T. Rutishauser, I. Baker, M. Liniger, and A. Denning (2011), A global reanalysis of vegetation phenology, J. Geophys. Res., 116, G03020, doi:10.1029/2010JG001545.

Tucker, C., J. Pinzon, M. Brown, D. Slayback, E. Pak, R. Mahoney, E. Vermote, and N. El Saleous (2005), An extended AVHRR 8-km NDVI dataset compatible with MODIS and SPOT vegetation NDVI data, Int. J. Remote Sens., 26(20), 4485-4498.

Urbanski, S., C. Barford, S. Wofsy, C. Kucharik, E. Pyle, J. Budney, K. McKain, D. Fitzjarrald, M. Czikowsky, and J. Munger (2007), Factors controlling $\mathrm{CO}_{2}$ exchange on timescales from hourly to decadal at Harvard forest, J. Geophys. Res., 112, G02020, doi:10.1029/ 2006JG000293.

Wang, Y. P., D. Baldocchi, R. Leuning, E. Falge, and T. Vesala (2007), Estimating parameters in a land-surface model by applying nonlinear inversion to eddy covariance flux measurements from eight FLUXNET sites, Global Change Biol., 13(3), 652-670.

White, M., and R. Nemani (2003), Canopy duration has little influence on annual carbon storage in the deciduous broad leaf forest, Global Change Biol., 9(7), 967-972.

Williams, M., et al. (2009), Improving land surface models with FLUXNET data, Biogeosciences, 6(7), 1341-1359.

Wilson, K., et al. (2002), Energy balance closure at FLUXNET sites, Agric For. Meteorol., 113(1), 223-243.

Zeng, X., M. Shaikh, Y. Dai, R. Dickinson, and R. Myneni (2002), Coupling of the common land model to the NCAR community climate model, J. Clim., 15(14), 1832-1854. 